\title{
WestVirginiaUniversity
}

THE RESEARCH REPOSITORY @ WVU

Graduate Theses, Dissertations, and Problem Reports

2000

\section{Substrate cleaning using a remote hydrogen rf-plasma}

Srinivasan Prasanna

West Virginia University

Follow this and additional works at: https://researchrepository.wvu.edu/etd

\section{Recommended Citation}

Prasanna, Srinivasan, "Substrate cleaning using a remote hydrogen rf-plasma" (2000). Graduate Theses, Dissertations, and Problem Reports. 1062.

https://researchrepository.wvu.edu/etd/1062

This Thesis is protected by copyright and/or related rights. It has been brought to you by the The Research Repository @ WVU with permission from the rights-holder(s). You are free to use this Thesis in any way that is permitted by the copyright and related rights legislation that applies to your use. For other uses you must obtain permission from the rights-holder(s) directly, unless additional rights are indicated by a Creative Commons license in the record and/ or on the work itself. This Thesis has been accepted for inclusion in WVU Graduate Theses, Dissertations, and Problem Reports collection by an authorized administrator of The Research Repository @ WVU. For more information, please contact researchrepository@mail.wvu.edu. 


\title{
SUBSTRATE CLEANING USING A REMOTE HYDROGEN RF-PLASMA
}

\author{
Srinivasan Prasanna \\ Thesis submitted to the \\ College of Engineering and Mineral Resources \\ at West Virginia University \\ in partial fulfillment of the requirements \\ for the degree of \\ Master of Science \\ in \\ Chemical Engineering \\ Charter D. Stinespring, Ph.D., Chair \\ Rakesh K. Gupta, Ph.D. \\ John W. Zondlo, Ph.D. \\ Department of Chemical Engineering \\ Morgantown, West Virginia \\ 2000
}

Keywords: substrate cleaning, rf-plasma, XPS

Copyright 2000 Srinivasan Prasanna 


\section{ABSTRACT \\ SUBSTRATE CLEANING USING A REMOTE HYDROGEN RF-PLASMA \\ Srinivasan Prasanna}

The substrates (wafers) used in semiconductor processing have a surface oxide layer (the so-called native oxide layer) and a hydrocarbon contamination layer that must be removed before growing an epitaxial film of good quality. In this work, low temperature remote rf-hydrogen plasma cleaning of II-VI and silicon semiconductor surfaces was investigated as a preparation for subsequent deposition in molecular beam and gas source molecular beam epitaxy environments. The plasma was characterized using mass spectrometric methods to determine the identity and relative fluxes of ionic and neutral species and to determine the kinetic energies of the ionic species. Etching studies were then performed using x-ray photoelectron spectroscopy (XPS) to monitor the changes of chemical composition of the surface as a function of exposure to the hydrogen plasma. For cadmium mercury telluride (CMT) and cadmium zinc telluride (CZT) the hydrogen plasma readily removes the oxide and an amorphous Te overlayer left behind by standard wet chemical processing of these substrates. Following the removal of these layers the H-plasma etches $\mathrm{HgTe}$, in the case of CMT, and CdTe, in the case of CZT. For silicon, the remote of H-plasma was found to be ineffective at removing either the native oxide, or the oxide left by standard wet chemical processing. The hydrocarbon impurities were removed for all substrates. These results suggest a suitable low temperature dry etching technique for II-VI semiconductors in a UHV environment. 


\section{Dedicated to my loving parents}




\section{ACKNOWLEDGEMENTS}

I wish to thank my advisor Dr. Charter Stinespring for his support, guidance and encouragement through the course of my work. I am also grateful to the members of my advisory committee, Dr. John Zondlo and Dr. Rakesh Gupta for their help. I would also like to thank Dr. Thomas H. Myers for his valuable suggestions with regard to my work.

My sincere thanks to Katie Ziemer; who helped me in carrying out my experiments and also in the analysis of my data. I would also like to thank Jeff Gold and Vikram Tolani for their help in the lab

I am really thankful to my friends Ganesh, Ravi, Srikanth, Ramani and Anand for making my stay in Morgantown truly memorable.

Finally, I wish to thank my family in India for their love and support through the course of my education in the United States 


\section{TABLE OF CONTENTS}

Title Page $\quad$ i

$\begin{array}{ll}\text { Abstract } & \text { ii }\end{array}$

Dedication $\quad$ iii

Acknowledgements $\quad$ iv

Table of Contents $\quad$ V

List of Tables vii

List of Figures viii

1. Introduction 1

2. Literature Survey 4

2.1 Wet Etching 4

2.1.1 Wet Etching of Silicon 4

2.1.2 Wet Etching of II-VI semiconductor surfaces 5

2.2 Plasma Based Etching $\quad 6$

2.2.1 Argon Ion Sputtering 6

2.2.2 Halogen based Plasma Etching 7

2.2.3 Hydrogen Plasma Etching $\quad 8$

2.2.4 Methane/ Hydrogen plasma cleaning of II-VI 12 semiconductor surfaces

2.3 H-atom cleaning of silicon and cadmium mercury telluride $\quad 14$

$\begin{array}{lr}\text { 3. Experimental Methods } & 19\end{array}$

3.1 Ultra-High Vacuum System 19

3.2 Hydrogen Source 19 
$\begin{array}{ll}\text { 3.3 X-ray Photoelectron Spectroscopy } & 21\end{array}$

$\begin{array}{ll}\text { 3.4 Mass Spectrometry } & 25\end{array}$

4. Results and Discussion $\quad 30$

4.1 Mass Spectrometer Characterization of the Hydrogen Plasma 30

4.1.1 Mass Filter Transmission Function 34

4.1.2 Beam Composition and Ion Energy Distribution 36

4.1.3 The Effects of Process Parameters on Ion Content 41

$\begin{array}{ll}4.2 \text { Cleaning of CZT } & 48\end{array}$

4.3 Etching of CMT using a hydrogen plasma 55

4.4 Si (100) Substrate Cleaning in the hydrogen plasma 60

5. Conclusions and Recommendations 66

5.1 Conclusions $\quad 66$

$\begin{array}{ll}\text { 5.2 Recommendations } & 67\end{array}$

$\begin{array}{ll}\text { References } & 69\end{array}$ 


\section{List of Tables}

Table 4.1 Different apertures used with the plasma source 30

Table 4.2 Different modes of operation of a mass spectrometer 31

Table 4.3 Sensitivity factors determined experimentally and from literature 52 


\section{List of Figures}

Figure 2.1 Te $3 \mathrm{~d}_{5 / 2}$ spectrum for a Br-methanol etched CMT substrate

Figure 2.2 Composition vs. etch time for the CMT substrate 18

Figure 3.1 Schematic of the UHV system with the X-ray source 20

Figure 3.2 Schematic of the UHV/MBE compatible hydrogen 22

plasma source

Figure 3.3 Electron mean free path vs. kinetic energy

Figure 3.4 Key elements of quadrupole mass spectrometer 28

Figure 3.5 Ionizer control of the Extrel mass spectrometer 29

Figure 4.1 Signal intensity vs. ion energy for the single hole aperture 32 using the low $\left(\mathrm{H}_{2} \mathrm{l}\right)$ and high $\left(\mathrm{H}_{2} \_\mathrm{h}\right)$ emission modes. The operating conditions were: power $=500 \mathrm{~W}$, pressure $=7.2 \times 10^{-5}$ Torr and $66.7 \% \mathrm{H}_{2}$ flow

Figure 4.2 Signal intensity vs. ion energy for the single hole aperture using the low (H_l) and high (H_h) emission modes. The operating conditions were: power $=500 \mathrm{~W}$, pressure $=7.2 \times 10^{-5}$ Torr and $66.7 \% \mathrm{H}_{2}$ flow

Figure 4.3 Mass filter transmission function of $\mathrm{H}_{2}$ for the single hole aperture

Figure 4.4 Neutral signal intensity vs. ion energy for the single hole aperture showing the calculated $\left(\mathrm{H}_{2} \_\mathrm{c}\right)$ and fitted $\left(\mathrm{H}_{2} \_\mathrm{f}\right)$ curves. The operating conditions were: power $=500 \mathrm{~W}$, pressure $=7.2 \times 10^{-5}$ Torr and $66.7 \% \mathrm{H}_{2}$ flow 
Figure 4.5 Neutral signal intensity vs. ion energy for the single hole aperture showing the calculated (H_c) and fitted (H_f) curves. The operating conditions were: power $=500 \mathrm{~W}$, pressure $=$ $7.2 \times 10^{-5}$ Torr and $66.7 \% \mathrm{H}_{2}$ flow

Figure 4.6 $\quad \mathrm{Y}^{*} \mathrm{~N}$ vs. ion energy for a single hole aperture. The operating conditions were: power $=500 \mathrm{~W}$, pressure $=7.2 \times 10^{-5}$ Torr and $66.7 \% \mathrm{H}_{2}$ flow

Figure 4.7 Effect of rf-power on ion content for the 9-hole aperture. The operating conditions were: pressure $=5.9 \times 10^{-5}$ Torr and $66.7 \%$ $\mathrm{H}_{2}$ flow

Figure 4.8 Effect of rf-power on ion content for the single-hole aperture.

The operating conditions were: pressure $=5.1 \times 10^{-5}$ Torr and $76.9 \% \mathrm{H}_{2}$ flow

Figure 4.9 Effect of pressure on ion content for the nine-hole aperture.

The operating conditions were: power $=300 \mathrm{~W}$ and $66.7 \%$

$\mathrm{H}_{2}$ flow

Figure 4.10 Effect of pressure on ion content for the single-hole aperture.

The operating conditions were: power $=300 \mathrm{~W}$ and $66.7 \%$

$\mathrm{H}_{2}$ flow

Figure 4.11 Effect of composition on ion content for the nine-hole aperture.

The operating conditions were: power $=300 \mathrm{~W}$ and pressure $=5.8 \times 10^{-5}$ Torr 
Figure 4.12 Te $3 \mathrm{~d}_{5 / 2}$ XPS spectra for a CZT substrate exposed to the $\mathrm{H}$-plasma at $30^{\circ} \mathrm{C}$ for various times

Figure 4.13 Composition vs. etch time for the CZT substrate

Figure 4.14 Composition vs. etch time for the CZT substrate at $300^{\circ} \mathrm{C}$

Figure 4.15 Te $3 d_{5 / 2}$ XPS spectra for a CMT substrate exposed to the $\mathrm{H}$-plasma at $30^{\circ} \mathrm{C}$ for various times

Figure 4.16 Composition vs. etch time for the CMT substrate

Figure 4.17 Si 2p XPS spectra for an as received Si-substrate $(\mathrm{t}=0)$ and after 30 minutes of etching $(\mathrm{t}=30)$

Figure 4.18 C 1s XPS spectra for an as-received Si-substrate $(t=0)$ and after 30 minutes of etching $(t=30)$

Figure 4.19 Si 2p XPS spectra for a Fenner etched Si-substrate $(t=0)$ and after 30 minutes of etching $(t=30)$

Figure 4.20 C 1s XPS spectra for a Fenner etched Si-substrate $(\mathrm{t}=0)$ and after 30 minutes of etching $(t=30)$ 


\section{INTRODUCTION}

Substrate cleaning (i.e. the removal of surface oxide \& contaminants) is a critical step in virtually all semiconductor device fabrication processes. The quality and properties of thin films subsequently deposited on the substrate are strongly influenced by substrate surface structure, composition, and roughness. All of these factors can be controlled or altered to some extent by the substrate cleaning process. The research described in this thesis addresses the use of a remote rf-hydrogen plasma to clean silicon, cadmium zinc telluride (CZT), and cadmium mercury telluride (CMT).

Silicon single crystal substrates are the basis for today's microelectronics industry. Presently industry is scaling up to handle $300 \mathrm{~mm}$ diameter silicon substrates for the fabrication of very large scale integrated (VLSI) circuits [1]. These include numerous multi-layered thin film structures such as pn-junction diodes, transistors, and light emitting diodes. Silicon substrates are critical to the development of microelectro mechanical devices [2], and flat panel displays [3]. Silicon is also being investigated as a candidate substrate for advanced electronic materials such as diamond [4], silicon carbide [5] and gallium nitride [6].

Silicon single crystal substrates (wafers) used in semiconductor processing typically have a surface oxide layer, the so-called native oxide and a hydrocarbon contamination layer. These are the result of wafer handling and interaction with the air and must be removed before growing an epitaxial film of good quality on the substrate. The oxide layer is commonly removed by a high-temperature treatment above $800^{\circ} \mathrm{C}$ in vacuum [7]. This may present a problem since dopant species within the silicon may rapidly diffuse at such temperatures, and as a result dopant profiles may be degraded. 
The II-VI compound semiconductors like CMT and CZT are used for the fabrication of electrooptical devices such as detectors (infrared, x-ray, and $\gamma$-ray), solar cells, and semiconductor lasers [8]. Just as with silicon, the removal of surface oxides and contaminants is a major problem. In this case, there is a general requirement to produce a surface with composition representative of the bulk composition. For these compound semiconductors wet chemical etching and chemo-mechanical polishing can be used to help remove the oxide, but at best, low levels of oxide are left behind. Further, thermal processing is generally not possible (particularly for CMT) since high temperatures lead to evaporative losses and resultant changes in stoichiometry. This, in turn, may significantly alter the physical and electrical properties of the substrates and the quality and properties of subsequently deposited thin films.

Clearly, there is a need for a low temperature method to clean silicon, CMT and CZT substrate surfaces. To accomplish this, numerous methods such as Ar ion sputtering and plasma etching have been investigated. These techniques, though effective in some respects, generally do not meet all the process requirements. For example, high temperatures may be required to anneal out substrate damage that is generated by the impact of energetic ions during sputtering, or in the case of compound semiconductors the resulting substrate composition may be non-stoichiometric. An additional requirement, which is imposed for substrate-cleaning procedures in certain processes, is that they be compatible with ultrahigh vacuum (UHV) based growth methods.

The main objective of this work is to study the remote rf-hydrogen plasma cleaning of silicon, CMT and CZT substrate surfaces as a preparation for subsequent deposition of other materials during device fabrication. Additional supporting objectives 
are to characterize the hydrogen plasma and to study the plasma-substrate interaction mechanisms. The next chapter discusses the literature related to this area of research. Chapter 3 discusses the experimental facilities and approach, and Chapter 4 discusses the results. Chapter 5 presents the conclusions and ideas for future research. 


\section{Literature Survey}

The cleaning of silicon and II-VI semiconductor surfaces involves the removal of hydrocarbon and oxide layers from their surface. This is typically accomplished by wet chemical etching followed by plasma based etching.

\subsection{Wet Etching}

\subsubsection{Wet Etching of Silicon}

Wet etching of silicon involves the removal of the surface oxide and impurities using etchants based on hydrofluoric acid (HF). Two of the prominent methods are the RCA cleaning procedure [9] and the Fenner etch [10].

In the RCA cleaning procedure, two solutions, used sequentially, have been devised to remove organic and inorganic contaminant remaining after solvent rinsing the wafer in hot trichloroethylene (TCE). The first solution, typically 5:1:1 to 7:2:1 parts by volume of deionized (DI) $\mathrm{H}_{2} \mathrm{O}: \mathrm{H}_{2} \mathrm{O}_{2}: \mathrm{NH}_{4} \mathrm{OH}$, was designed to remove organic contaminants. The second, consists of $\mathrm{DI} \mathrm{H}_{2} \mathrm{O}: \mathrm{H}_{2} \mathrm{O}_{2}: \mathrm{HCl}$ in the proportion $6: 1: 1$ to 8:1:1 by volume was chosen to remove heavy metals. Cleaning in both mixtures is carried out at $75^{\circ} \mathrm{C}$ to $85^{\circ} \mathrm{C}$ for time periods of 10 minutes to 20 minutes. This is followed by a quench in DI $\mathrm{H}_{2} \mathrm{O}$ and rinse in running DI or quartz distilled $\mathrm{H}_{2} \mathrm{O}$. As a final step, the wafers are spun dried and immediately transferred to an enclosure flushed with inert gas. This method is very effective and it has wide applications to the cleaning and preparation of silicon wafers, quartz tubes, and wafer handling implements employed in semiconductor processing.

In the Fenner etch procedure, the substrate is first degreased in TCE, acetone and methanol at around $70^{\circ} \mathrm{C}$. It then undergoes a 5-minute DI $\mathrm{H}_{2} \mathrm{O}$ rinse and is then blow- 
dried with UHP nitrogen. This blow dry procedure is repeated after every $\mathrm{DI}_{2} \mathrm{O}$ rinse. The substrate is then immersed in a 5:1:1 DI $\mathrm{H}_{2} \mathrm{O}: \mathrm{NH}_{4} \mathrm{OH}: \mathrm{H}_{2} \mathrm{O}_{2}$ solution kept at $80^{\circ} \mathrm{C}$ for 10 minutes. This is followed by a 5-minute $\mathrm{H}_{2} \mathrm{O}$ rinse, a 15-second dip in 50:1 DI $\mathrm{H}_{2} \mathrm{O}$ : $\mathrm{HF}$ solution, and then a 20 -second DI $\mathrm{H}_{2} \mathrm{O}$ rinse. Next the substrate is immersed in a 6:1:1 DI $\mathrm{H}_{2} \mathrm{O}: \mathrm{HCl}: \mathrm{H}_{2} \mathrm{O}_{2}$ solution for 10 minutes and is followed by a 20-minute DI $\mathrm{H}_{2} \mathrm{O}$ rinse. The final step is a 2.5 minute dip in 1:1:10 HF: DI $\mathrm{H}_{2} \mathrm{O}$ : absolute reagent alcohol. The substrate was then rinsed with DI $\mathrm{H}_{2} \mathrm{O}$.

The Fenner etch results in the hydrogen passivation of the silicon surface. This prevents or reduces re-adsorption of oxygen by hydrogen terminating the silicon-dangling bonds on the surface. The maximum temperature used during the Fenner etch is around $100^{\circ} \mathrm{C}$, and this is well below the temperature at which degradation of the dopant profiles can take place. These surfaces are relatively stable in air, and hydrogen can be desorbed in UHV between 200 and $600^{\circ} \mathrm{C}$ [11].

\subsubsection{Wet Etching of II-VI semiconductor surfaces}

The wet etching of II-VI semiconductor surfaces is done using 0.5 to 3.5 volume percent bromine in methanol solutions [12]. The etch rates vary linearly with bromine concentration and are independent of substrate orientation. The chemical etching with bromine/ methanol solution does not produce a stoichiometric surface, but it is still the most widely used chemical etchant. Often the etchant is used as a polishing agent during mechanical lapping, and the procedure is referred to as chemo-mechanical polishing [13]. In a recent comprehensive study, Seelmann-Eggebert et al. [14] compared chemomechanical polishing and spray etching of samples with $0.5 \%-1 \%$ bromine in methanol. Typical etch rates were $2 \mu \mathrm{m} / \mathrm{min}$ (spray etch) and $10 \mu \mathrm{m} / \mathrm{min}$ (chemo-mechanical 
polishing). After removing a layer of $\sim 1 \mu \mathrm{m}$ thickness from the wafer, the samples were thoroughly rinsed in pure methanol and immediately (within $2 \mathrm{~min}$ ) transferred into the XPS analysis chamber. The reproducibility of the surface composition was poor in the case of chemo-mechanical polishing and spray etching. However, the oxide phases show a pronounced tendency to occur after spray etching.

\subsection{Plasma Based Etching}

Plasma based etching techniques include argon ion sputtering [15], halogen [16] and hydrogen based plasma [17] etching of silicon and $\mathrm{CH}_{4} / \mathrm{H}_{2}$ based plasma etching of II-VI compounds [18]. These processes involve the interaction of active species formed in the plasma discharge with the substrate surface. The physical interaction may involve pure energy and momentum transfer (sputtering), pure chemical interaction (plasma etching), or a combination of the two (reactive ion etching).

The plasmas used in semiconductor processing are generated by the application of a direct current (dc), radio frequency (rf) or microwave electric field across a body of gas. The type of plasma of particular interest for use in the semiconductor industry is classified as low-pressure glow discharge plasma. For these plasmas, the electron density ranges from $10^{9}$ to $10^{12} \mathrm{~cm}^{-3}$ and electron energies vary from about $1-20 \mathrm{eV}$ [19]. Typical operating pressures are in the range of 0.1 to 2 Torr.

\subsubsection{Argon Ion Sputtering}

Argon ion sputtering involves cleaning the surface with an argon ion beam. The mechanism by which cleaning occurs in this case is energy and momentum transfer. Argon ion sputtering is often combined with techniques like Auger electron spectroscopy, X-ray photoelectron spectroscopy to obtain depth profiles of thin films $[20,21]$. This 
technique is ultahigh vacuum (UHV) compatible and is effective in removing the oxide layer.

Holmen et al. [15] demonstrated the argon ion sputtering of $\mathrm{SiO}_{2}$ films in ultrahigh vacuum and low-pressure oxygen ambient. Although quite effective in removing surface oxides, the argon ion sputtering produces rough surfaces that need to be annealed out at high temperatures.

\subsubsection{Halogen based Plasma Etching}

Halogen based plasma etching (rf and microwave) [22] of silicon is based on the use of halogenated compounds like $\mathrm{CF}_{4}, \mathrm{CCl}_{4}, \mathrm{~F}_{2}, \mathrm{Cl}_{2}, \mathrm{SiH}_{3} \mathrm{~F}$ and $\mathrm{SF}_{6}$ at near ambient temperature conditions. Additions of hydrogen and oxygen are also used to control the etch process. The cleaning mechanism primarily involves chemical interactions between the substrate surface and highly reactive plasma species (neutrals); however, at pressures less than a few mTorr, ion interactions become important. This is indicative of the transition from plasma etching to reactive ion etching (RIE). In the latter case, the mechanism involves surface chemical reactions enhanced by energy and momentum transfer.

Mogab et al. [22] demonstrated the etching of $\mathrm{Si}$ and $\mathrm{SiO}_{2}$ in $\mathrm{CF}_{4}$ plasmas. Emission spectroscopy showed that the fluorine atoms were the principal etchant species for silicon while $\mathrm{CF}_{\mathrm{x}}$ radicals were responsible for etching $\mathrm{SiO}_{2}$. The addition of oxygen to the $\mathrm{CF}_{4}$ plasma increased the atomic fluorine concentration and thereby enhanced the etching rate for silicon. Hydrogen addition reduced the silicon etch rate allowing $\mathrm{SiO}_{2}$ to be preferentially etched. 
Although quite effective in producing patterns on silicon and $\mathrm{SiO}_{2}$, halogen-based plasma etched samples are not particularly clean. They may be contaminated with fluorocarbon polymers and embedded fluorine $\left(\mathrm{SiF}_{\mathrm{x}}\right)$ which must be desorbed. In addition, these methods are not UHV compatible.

\subsubsection{Hydrogen-Plasma Etching}

Hydrogen-plasma etching is based on the ion etching effect and the hydrogen passivation effect at low temperatures. Since hydrogen is the lightest element and is reported to react chemically with carbon or oxygen, so severe substrate damage during ion bombardment is reduced, while keeping the substrate surfaces clean [23].

RF plasmas [19] are generated at gas pressures from $10^{-2}$ to 1 Torr, with plasma densities of the order of $10^{10} \mathrm{~cm}^{-3}$. The ionization ratios are between $10^{-6}$ to $10^{-4}$.

Carter et al. [17] cleaned the surface of $\mathrm{Si}_{-} \mathrm{SiO}_{2}$ patterned wafers using rfhydrogen plasma etching. Prior to the insertion into the vacuum system for the in situ cleaning, the patterned surfaces were prepared with the two-step UV/ozone followed by a HF-based spin etch. The samples were introduced into the chamber (base pressure $7 \times 10^{-9}$ Torr) and the etching was done as follows. The substrate temperature was ramped $50^{\circ} \mathrm{C} / \mathrm{min}$ to $150^{\circ} \mathrm{C}$ and held there for 2 minutes. It was then ramped to $450^{\circ} \mathrm{C}$, at the same rate, and held for 3 minutes. The hydrogen plasma was activated $\left(20 \mathrm{~W}, 15 \times 10^{-3}\right.$ Torr) for the first 2 minutes. After 2 minutes of plasma exposure, the RF power and $\mathrm{H}_{2}$ gas were switched off with the sample being held at $450^{\circ} \mathrm{C}$ for the final minute. The surface was held at $450^{\circ} \mathrm{C}$ for the extra minute to prevent the sample from cooling in an $\mathrm{H}-\mathrm{H}_{2}$ ambient, possibly leading to an $\mathrm{H}$-terminated surface. 
The plasma etching was monitored by residual gas analysis (RGA). The patterned surfaces were characterized with low energy electron diffraction (LEED) and atomic force microscopy (AFM). The samples were also characterized with Auger electron spectroscopy (AES) for detection of surface contaminants. The sharpness of the LEED patterns as well as the $2 \times 1$ reconstruction indicated that the hydrogen plasma cleaned the bare $\mathrm{Si}$ regions. In addition, the AFM measurements indicated that the $\mathrm{Si}$ and $\mathrm{SiO}_{2} \mathrm{rms}$ roughness do not vary significantly due to the hydrogen plasma exposure. Based on this, it can be concluded that this method resulted in a clean surface without any significant reaction with either $\mathrm{Si}$ or $\mathrm{SiO}_{2}$.

Anthony et al. [24] demonstrated a cleaning technique for removing both carbon and oxygen from a Si surface. It uses a combination of ex-situ wet chemical clean and insitu cleaning. The silicon substrate is RCA cleaned which is followed by a HF dip. Then, the in-situ clean is achieved by remote rf-plasma excited $\mathrm{H}_{2}$ in a UHV chamber. The cleaning parameters utilized included $\mathrm{H}_{2}$ flow rates (5 and $\left.200 \mathrm{sccm}\right), \mathrm{H}_{2}$ partial pressures ( 3 and $45 \times 10^{-3}$ Torr), rf power $\left(10-70 \mathrm{~W}\right.$ ) and substrate temperature $\left(150-325^{\circ} \mathrm{C}\right)$. The duration of the etch ranged from 5 to $60 \mathrm{~min}$. The results were evaluated by comparing the RHEED patterns from the Si surface before and after cleaning, and correlating the results with Auger analysis of the surface. From mass spectroscopic studies, it was found that the hydrogen cleaning is due to a chemical etching of the Si by atomic hydrogen produced in the plasma. This cleaning procedure yields silicon substrates that can be used for successful very low temperature Si homoepitaxy.

ECR plasmas [19] are generated at pressures between $10^{-5}$ to $10^{-3}$ Torr, with plasma densities of the order $10^{10} \mathrm{~cm}^{-3}$. The ionization ratios are between $10^{-3}$ to $10^{-1}$. 
Suemune et al. [25] demonstrated the $\mathrm{Si}(001)$ surface cleaning at temperatures as low as $300^{\circ} \mathrm{C}$ using an ECR hydrogen plasma source. In this method, the substrates are first degreased and etched in HF acid before being introduced into the vacuum chamber. After the hydrogen plasma cleaning at $300^{\circ} \mathrm{C}$ for 1 hour, streak RHEED patterns were observed. This indicated that the cleaned Si surface was almost atomically flat.

Kim et al. [26] showed that a clean silicon surface could be obtained by in-situ ECR hydrogen plasma cleaning at room temperature. Here, the wafers are first RCA cleaned in an RCA station and then introduced into the CVD chamber. The base pressure in this chamber was about $1 \times 10^{-8}$ to $2 \times 10^{-8}$ Torr. Under process conditions, hydrogen pressure was $1 \times 10^{-3}$ Torr, flow rate was kept at $20 \mathrm{sccm}$, and a positive $10 \mathrm{~V}$ of d.c bias was applied while etching was carried out for 5 minutes at room temperature. Rutherford backscattering spectroscopy (RBS), secondary ion mass spectroscopy (SIMS), transmission electron spectroscopy (TEM) and emission Fourier transform infrared spectroscopy (FTIR) results were presented to demonstrate the effectiveness of the cleaning process.

Nam et al. [23] used hydrogen and argon ECR plasmas to clean Si surface without any additional heating. Here, the wafers are loaded into the ECR chamber through a loadlock chamber without any surface pretreatment. The flow rate of the hydrogen gas was set to $15 \mathrm{sccm}$, which results in a pressure of $2.5 \times 10^{-3}$ Torr. The net microwave power was about $800 \mathrm{~W}$ during the treatment. The exposure time was set at 4, 8 and $12 \mathrm{~min}$ for each set of samples. In the case of cleaning with the ECR Ar plasma, the gas flow rate was set to $10 \mathrm{sccm}$ to maintain a pressure of $1 \times 10^{-3}$ Torr. The plasma exposure times were 30,60 and $90 \mathrm{sec}$. The results were evaluated by making I-V measurements and 
these showed that the hydrogen plasma induced smaller changes than the argon plasma. The SIMS showed that there were no noticeable increases of impurities after cleaning. Finally, the hydrogen plasma treated samples were annealed for 20 minutes from $300^{\circ} \mathrm{C}$ to $750^{\circ} \mathrm{C}$ and the argon plasma treated samples were annealed for 1 hour at temperatures between 700 to $1000^{\circ} \mathrm{C}$ to give a clean surface.

Delfino et al. [27] also demonstrated the cleaning of silicon surfaces with hydrogen based ECR plasma. These surfaces are then characterized by in-situ x-ray photoelectron spectroscopy (XPS) and in-situ static secondary ion-mass spectrometry (SIMS). Emission spectroscopy and actinometry are used to characterize the hydrogen plasma. The ECR module consisted of a $1.5 \mathrm{~kW}$ microwave power supply operating at 2.45 GHz. The operating base pressure was $7 \times 10^{-8}$ Torr. No heat was applied to the substrate, which was found not to exceed $200^{\circ} \mathrm{C}$ during processing. A 3 to 4 minute exposure to plasma without applying heat or bias to the substrate completely removed the native silicon oxide and resulted in a hydrogen-terminated surface resistant to reoxidation. The resulting surface was hydrogen terminated and was resistant to oxidation. The effect of change in microwave power, the hydrogen pressures and ion energy on the native silicon oxide removal were studied. The density of the hydrogen excited species and the ground state hydrogen atom densities were correlated with the oxygen removal rate under all conditions except at high pressure, where the density of hydrogen ions was low. This suggested an ion-induced etching mechanism whereby the native silicon oxide removal was enhanced with low-energy hydrogen ion bombardment.

Ishii et al. [28] studied the properties of silicon surface cleaned by hydrogen based ECR plasma using XPS, RHEED, and FTIR. It was confirmed that the etching eliminated 
both a native oxide layer and a carbon contamination layer from the surface. However, the plasma cleaning caused roughness of the surface and hydrogen penetration into the bulk.

Shimomura et al. [29] demonstrated the surface cleaning of silicon by atomic hydrogen etching. The substrates used were prepared by conventional wet cleaning procedures and treated under UV light for about 10 minutes before loading into the vacuum chamber. Here, the substrate was heated up to about $700^{\circ} \mathrm{C}$. Then atomic hydrogen was generated by the decomposition of molecular $\mathrm{H}_{2}$ from a hot $\left(1500^{\circ} \mathrm{C}\right)$ tungsten filament of a cracking cell. The hydrogen backpressure was kept constant at about $6 \times 10^{-6}$ Torr. AES was used to analyze the sample before and after the clean, and it was found that as short as 1-minute of atomic hydrogen exposure at $700^{\circ} \mathrm{C}$ was sufficient to obtain a clean, single domain Si surface.

\subsubsection{Methane/Hydrogen Plasma Cleaning of II-VI semiconductor surfaces}

This involves the cleaning of II-VI semiconductors under moderate to high vacuum conditions. The techniques primarily included in this category are reactive ion etching and argon ion etching. Foad et al. [8] showed that reactive ion etching using $\mathrm{CH}_{4} / \mathrm{H}_{2}$ is an effective dry etching technique suitable for variety of II-VI semiconductors. The quality of the surfaces had been examined using XPS and Raman spectroscopy with both techniques indicating little damage.

Spencer et al. [30] investigated the methyl radical etching using a secondary afterglow reactor. Here, a secondary afterglow reactor, in which atomic fluorine produced in a microwave discharge, is reacted with methane downstream of the discharge and this etches the surface at temperature dependent rates between $10 \mathrm{~nm}$ and $100 \mathrm{~nm} / \mathrm{min}$. This 
etching is purely chemical without ion bombardment, and it shows crystallographic orientation dependence on the etch rate. Scanning electron microscopy was used to analyze the etched surfaces. Specular surfaces were observed for almost all the II-VI semiconductors except for CMT. Solzbach et al. [31] studied the $\mathrm{Ar}^{+}$sputtering of CdTe, HgTe and $\mathrm{Hg}_{0.8} \mathrm{Cd}_{0.2} \mathrm{Te}$ surfaces using XPS and LEED. The sputtering yielded a perfect unreconstructed CdTe surface of stoichiometric composition, whereas the composition of sputtered $\mathrm{HgTe}$ and $\mathrm{Hg}_{0.8} \mathrm{Cd}_{0.2} \mathrm{Te}$ surfaces generally deviated from the stoichiometry of the respective compound. The XPS spectra showed that the sputtered surfaces were relatively free of oxygen and carbon.

The II-VI semiconductors generally have weak crystal strengths and greater defect densities. Ion bombardment can cause extensive degradation of electrical properties of these materials. Consequently the dry etching of II-VI semiconductors presents a spectrum of difficulties and challenges.

Keller et al. [32] demonstrated the cleaning of CZT using $\mathrm{H}_{2} / \mathrm{Ar}-\mathrm{CH}_{4} / \mathrm{H}_{2} / \mathrm{Ar}$ and $\mathrm{CH}_{4} / \mathrm{H}_{2} / \mathrm{N}_{2} / \mathrm{Ar}$ based ECR plasmas. The techniques used to characterize the roughness, composition and order of the resulting substrate surfaces were ellipsometry, angleresolved XPS, and LEED. The CZT was more susceptible to evolving surface roughness under $\mathrm{H}_{2} / \mathrm{Ar}$ plasma exposure than $\mathrm{CdTe}$. The severe roughening observed at $100^{\circ} \mathrm{C}$ sample temperature was found to be correlated with a build-up of ZnTe at the surface. This suggests that the roughness may result from a preferential etching of the CdTe component. The surface degradation was reduced by the addition of $\mathrm{CH}_{4}$ to the process gases. During the excitation in an ECR plasma, however the $\mathrm{CH}_{4}$ molecules break up not only into $\mathrm{CH}_{3}$ radical, the reactant responsible for etching the respective group II 
element, but also into $\mathrm{CH}_{2}$ and $\mathrm{CH}$ radicals which are precursors of hydrocarbon polymers. Atomic nitrogen created by the addition of $\mathrm{N}_{2}$ gas inhibited the deposition of hydrocarbon polymers in the chamber and on the sample. The atomic nitrogen resulted in the elimination of polymer precursors, the reduction of the atomic hydrogen concentration, and a potential increase of methyl radical concentration. All this substantially improved the plasma process so that atomically clean, very smooth, and stoichiometrically composed CZT surfaces of long-range order were eventually obtained.

Keller et al. [18] demonstrated that the $\mathrm{CH}_{4} / \mathrm{H}_{2}$ plasmas enable etching of potentially all common II-VI semiconductors by forming volatile methyl and hydride reaction products. Again, the addition of $\mathrm{N}_{2}$ gas inhibits the deposition of polymers and results in an atomically clean, smooth and stoichiometrically composed surface.

\subsection{H-atom Cleaning of Silicon and Cadmium Mercury Telluride}

At West Virginia University, Hirsch et al. [33] investigated the cleaning of silicon, CdTe and CMT using wet etching and atomic hydrogen etching. A commercial atomic hydrogen source, an EPI-AHS-L manufactured by EPI MBE Products Group, was used to generate atomic hydrogen by thermal cracking of molecular hydrogen on a heated tungsten filament.

The Fenner etched silicon substrates gave a RHEED pattern exhibiting both diffuse scattering and rings. These features disappeared after annealing at $200^{\circ} \mathrm{C}$, leaving only the sharp, streaky RHEED patterns. The disappearance of the rings were thought to correspond to the desorption of residual carbon from the surface. Based on similar RHEED analysis, Hirsch et al. also found that a twenty minute exposure of atomic hydrogen at $600^{\circ} \mathrm{C}$ removed the oxide layer from a silicon substrate etched in HF: $\mathrm{H}_{2} \mathrm{O}$ 
solution (or) cleaned using the Fenner etch. There was no observation of change from the bulk-like (1x1) RHEED patterns indicating an absence of surface reconstruction.

The as-received CdTe substrates typically exhibited diffuse scattering. RHEED measurements on the as-etched substrates gave irregular, spotty patterns with superimposed rings, which is indicative of a residual Te overlayer, probably from the $\mathrm{Br}$ : methanol etch. Annealing at $200^{\circ} \mathrm{C}$ removed the Te which was indicated by the disappearance of the diffraction rings. A 20-minute exposure to atomic hydrogen at room temperature removed the diffuse scattering and/or the Te-overlayer leaving a bright, three-dimensional spot pattern. For temperatures above $80^{\circ} \mathrm{C}$, however, the oxide/ $\mathrm{Te}$ overlayer was rapidly removed and a sharp two-dimensional pattern with well-defined steaks was observed.

The as-prepared CMT showed a diffuse pattern characteristic. On brief exposure to atomic hydrogen most of the diffuse scattering and rings were eliminated. The RHEED then consisted of a highly irregular spot pattern, indicative of a rough surface with a possible partially polycrystalline overlayer. Raising the sample temperature to $80^{\circ} \mathrm{C}$ dramatically changed the process. Again, a brief exposure to the hydrogen source appeared to remove the initial oxide layer. In contrast to the room temperature etch, a well-defined two-dimensional pattern exhibiting sharp streaks was observed after a 20minute exposure.

In order to better understand the processes occurring during atomic hydrogen etching, a series of etch experiments were performed and XPS measurements were made as a function of etch time. Figure 2.1 shows a series of Te $3 d_{5 / 2}$ photoelectron spectra for increasing exposures to atomic hydrogen. The $\mathrm{t}=0$ spectrum is typical of all $\mathrm{Br}$-methanol 
etched samples analyzed in this study. The photoelectron peak at $572.6 \mathrm{eV}(1.6 \mathrm{eV}$ FWHM) has been previously associated with $\mathrm{Te}$ in the oxide state, while the peak at $572.7 \mathrm{eV}(1.6 \mathrm{eV} \mathrm{FWHM})$ is representative of metallic Te $[34,35]$. As the etch proceeds, the peak shifts to a lower binding energy of $572.3 \mathrm{eV}$ (1.5 eV FWHM) which is representative of Te in CdTe and CMT [36] and the oxide peak slowly vanishes. The corresponding $\mathrm{Cd} 3 \mathrm{~d}_{5 / 2}$ and the $\mathrm{Hg} 4 \mathrm{f}_{7 / 2}$ photoelectron spectra did not exhibit a characteristic oxide peak.

The effect of etching on the near-surface composition as probed by the XPS is shown in Figure 2.2. In all cases, an increase in the near surface concentration of $\mathrm{Hg}, \mathrm{Cd}$ Te was observed following the removal of the oxide overlayer. With continued etching, the Te decreased slightly to a relatively constant value, which was typically within a few percent of its initial concentration. The Cd concentration, on the other hand, increased. The relative atomic concentrations approximately indicated one Te for each remaining $\mathrm{Hg}$ and $\mathrm{Cd}$, implying Te removal as well as $\mathrm{Hg}$ removal. In all cases, the steady state composition of the atomic hydrogen etched CMT surface was HgTe depleted. 


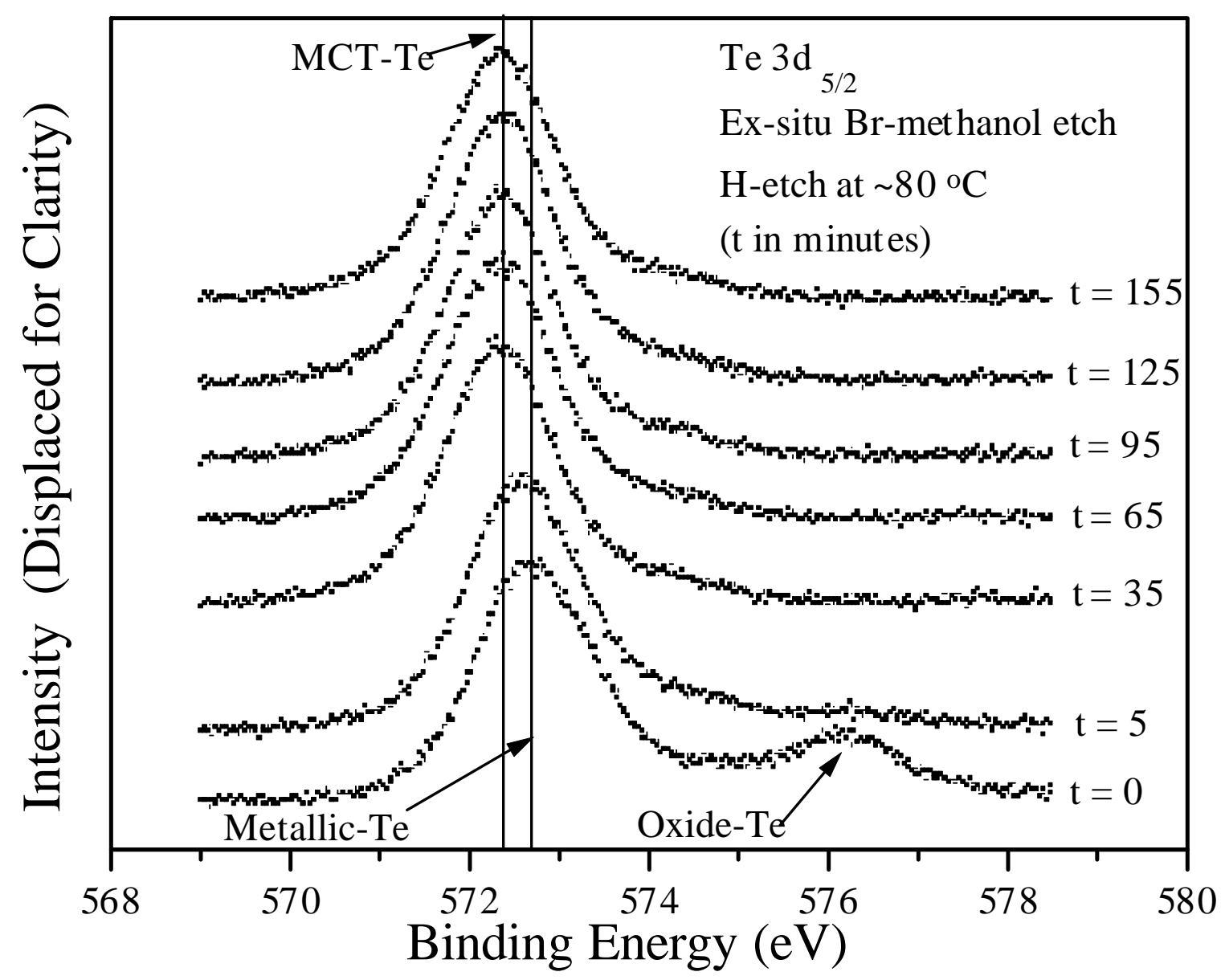

Figure 2.1 Te $3 \mathrm{~d}_{5 / 2}$ spectrum for a Br-methanol etched CMT substrate. [33] 


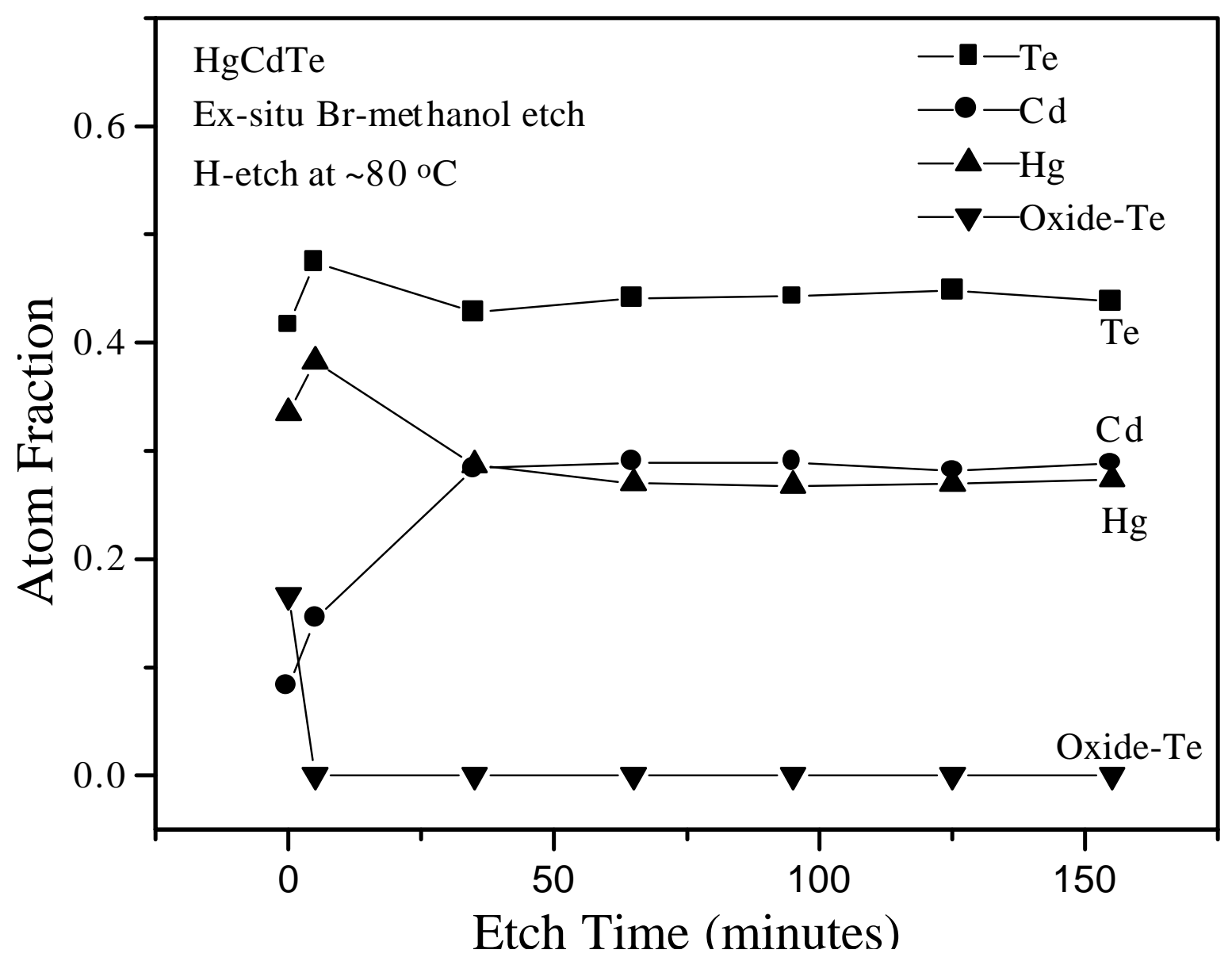

Figure 2.2 Composition vs. etch time for the CMT substrate. [33] 


\section{Experimental Methods}

\subsection{Ultrahigh Vacuum System}

The experiments performed in this research were conducted in the UHV-growth/ analysis system shown schematically in Figure 3.1. The UHV growth chamber is pumped by an Osaka TG200 turbomolecular pump with a pumping speed of 200 1/s for air and $150 \mathrm{l} / \mathrm{s}$ for hydrogen. The mass spectrometer is differentially pumped using a Varian V550 turbomolecular pump with a pumping speed of $550 \mathrm{l} / \mathrm{s}$ for air and $510 \mathrm{l} / \mathrm{s}$ for hydrogen. The base pressures were typically on the order of $10^{-9}$ Torr as monitored by ion gauges in both the reaction chamber and the mass spectrometer chamber.

The rf-plasma source was conflat flange mounted on the UHV reaction chamber as shown in Figure 3.1 and, the discharge products produced by the source were characterized using the mass spectrometer. Routinely, the gas line was checked for air leaks with the mass spectrometer. There is also an ion source in the growth chamber, which is used for argon ion sputtering substrate surfaces.

Surface characterization of the substrates was performed in the analysis chamber shown using x-ray photoelectron spectroscopy (XPS). The linear transfer was used to transfer the sample from the growth to the analysis chamber. The analysis chamber was pumped by ion and titanium sublimation pumps. Base pressures in the analysis chamber were typically on the order of $\sim 10^{-9}$ Torr.

\subsection{Hydrogen Source}

In this work, an Oxford Applied Research [37] Model CARS25 source was used to produce the hydrogen plasma. Figure 3.2 shows a schematic diagram of the Oxford source which operates by means of an electrical discharge created from an inductively 


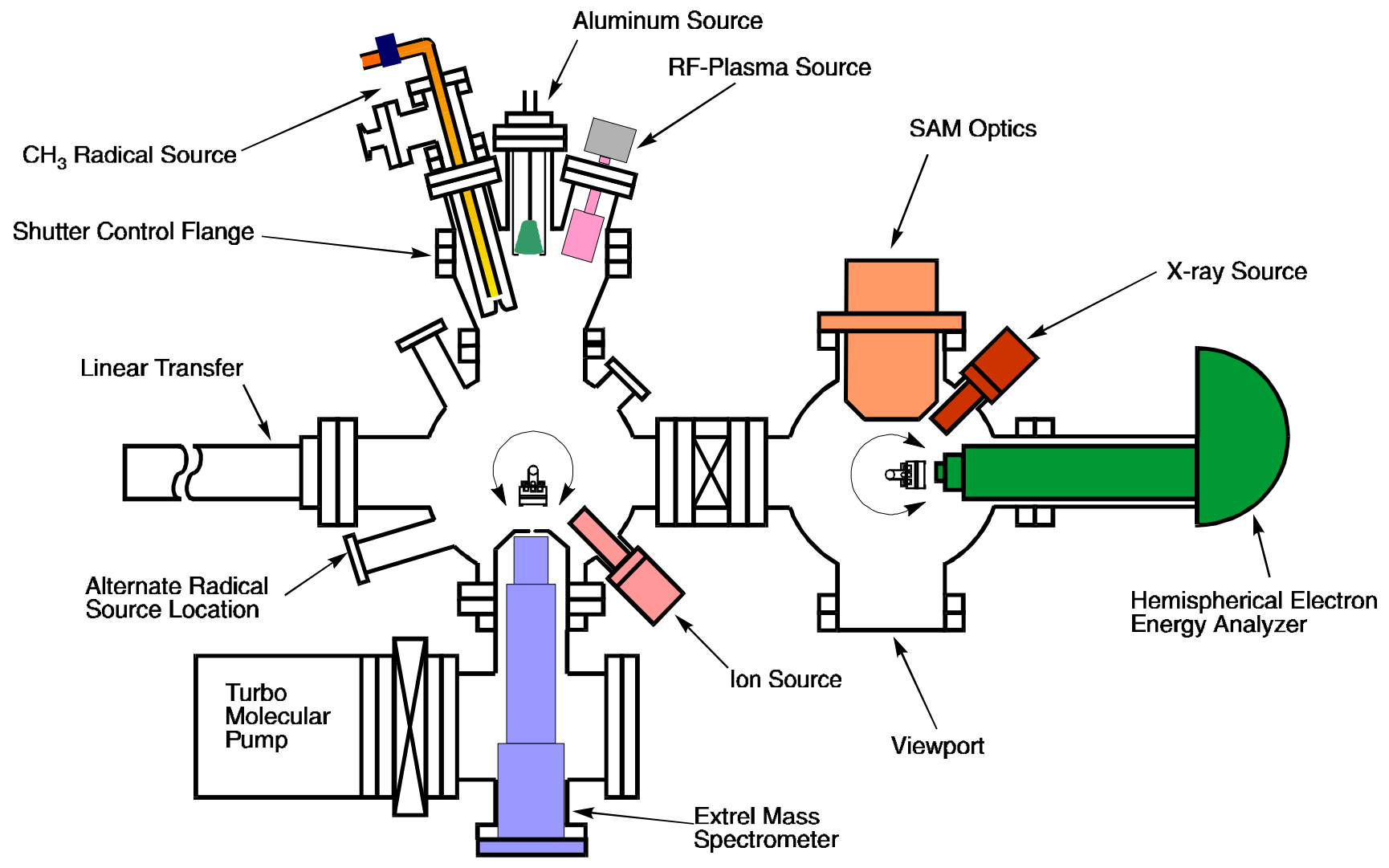

Figure 3.1 Schematic of the UHV system with the X-ray source. 
coupled RF excitation at $13.56 \mathrm{MHz}$ with a maximum power of $600 \mathrm{~W}$. A matching network, an RLC circuit, minimizes the reflected power from the source. The plasma is contained in a high purity PBN (pyrolitic boron nitride) discharge tube with the discharge being electrodeless for minimum contamination. The PBN discharge tube is surrounded by liquid nitrogen cooled RF coil and the $\mathrm{H}_{2}$ gas is fed into the tube through the entry hole at one end of the tube. A PBN aperture plate with several holes serves as the exit plate to the source. This permits the hydrogen ions, neutrals to flow out of the discharge chamber towards the substrate. Several PBN aperture plates with different hole diameters and different number of holes were available for these experiments. The source is interfaced to the UHV chamber by a $4 \frac{1}{2}$ " conflat flange. Due to the small size of the openings in the aperture, significant differential pumping exists between the source and the chamber. Typically chamber pressures are on the order of $10^{-5}$ Torr while source pressures could be as high as several Torr.

The plasma is ignited with a mixture of $\mathrm{H}_{2}$ in $\mathrm{Ar}\left(\leq 50 \% \mathrm{H}_{2}\right)$ at a chamber pressure of $\sim 10^{-4}$ Torr. After the source was ignited the desired rf-power level could be set, the pressure could be reduced to $10^{-5}$ Torr range, and the $\mathrm{H}_{2}$ concentration could be increased to a maximum of $76.7 \%$. Above this concentration the plasma could not be sustained.

\subsection{X-ray photoelectron spectroscopy}

XPS was used to investigate the chemical composition of surfaces before, during, and after the etching process. In XPS a solid is irradiated in vacuum with mono-energetic soft x-rays, and the resulting photoelectrons are analyzed in terms of their kinetic energy [39]. The spectrum is obtained as a plot of the number of detected electrons per energy 


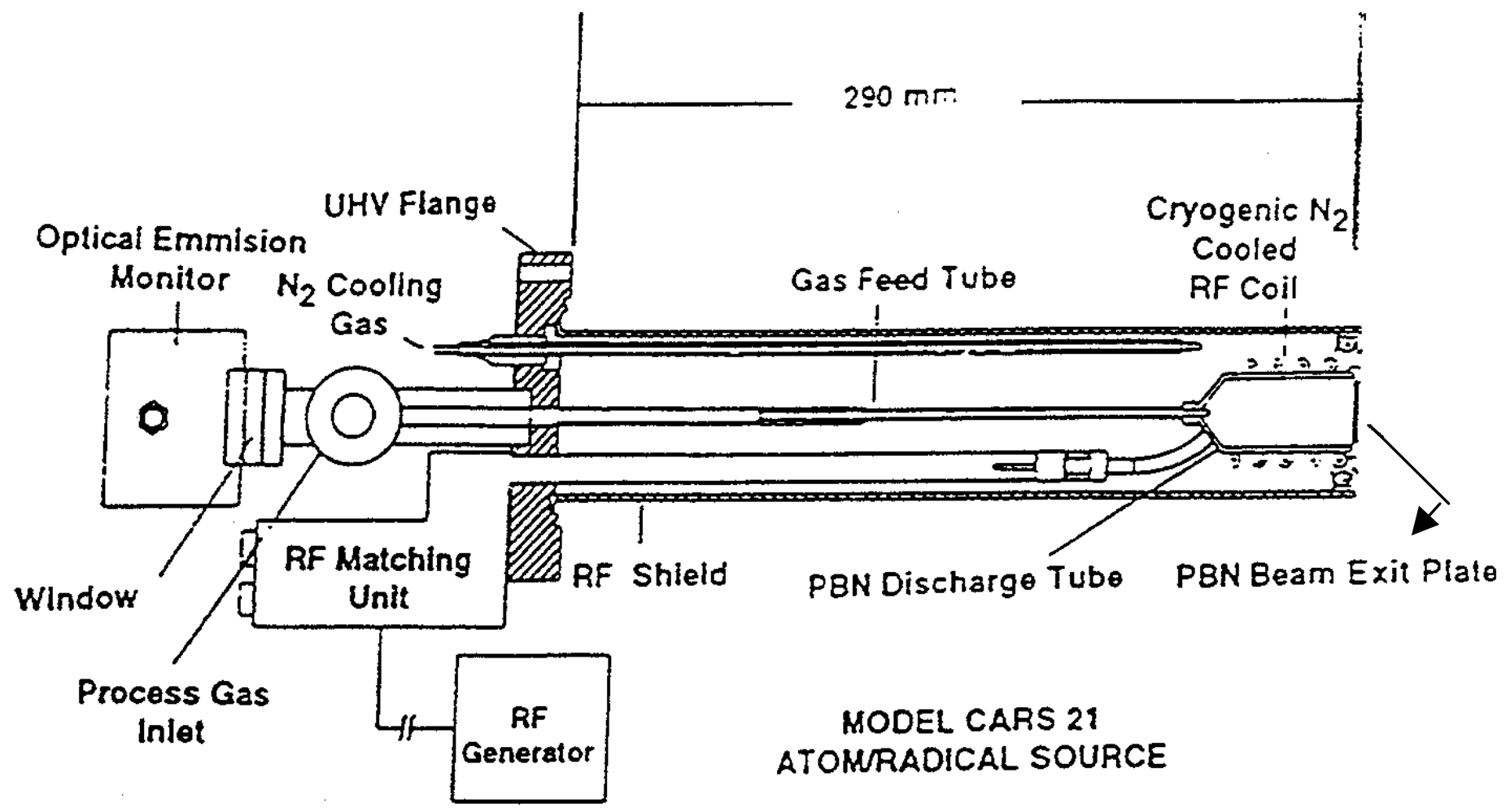

Figure 3.2 Schematic of the UHV/MBE compatible hydrogen plasma source. [38] 
interval versus either their kinetic energy (KE) or binding energy (BE). These two terms are related by the expression

$$
\mathrm{BE}=\mathrm{h} \gamma-\mathrm{KE}-\phi_{\mathrm{s}}
$$

where $h \gamma$ is the product of Plank's constant and the x-ray frequency (i.e. $h \gamma$ is the energy of the x-ray photon) and $\phi_{\mathrm{s}}$ is the work function of the spectrometer. The work function of the spectrometer is determined by calibration using a standard material such as gold or silver.

One of the most useful features of XPS is its ability to obtain information on chemical states from the variations in binding energies, or chemical shifts, of the photoelectron lines. For example, Figure 2.1 shows two peaks, one for metallic Te at $572.7 \mathrm{eV}$ and the other for $\mathrm{TeO}_{2}$ at $576.1 \mathrm{eV}$. This shift in the binding energy between $\mathrm{Te}, \mathrm{TeO}_{2}$ enables one to see the addition (or) removal of oxide with etching comfortably.

The energy of the electrons in XPS is in the range of 50 to $1000 \mathrm{eV}$. Figure 3.3 which shows the variation of escape depth (mean free path) versus kinetic energy, clearly indicates that the corresponding mean free paths are in the range of 0.5 to $2.5 \mathrm{~nm}$. This makes XPS a unique surface analysis technique for chemical analysis.

XPS may also be used to determine quantitative information, such as the relative concentrations of the various constituents contained in the sampling volume. Methods have been developed for quantifying the XPS measurement utilizing peak area and peak height sensitivity factors. A general expression for determining the atom fraction of any constituent in a sample $C_{i}$, can be written as

$$
C_{i}=\frac{I_{i} / S_{i}}{\sum I_{i} / S_{i}}
$$




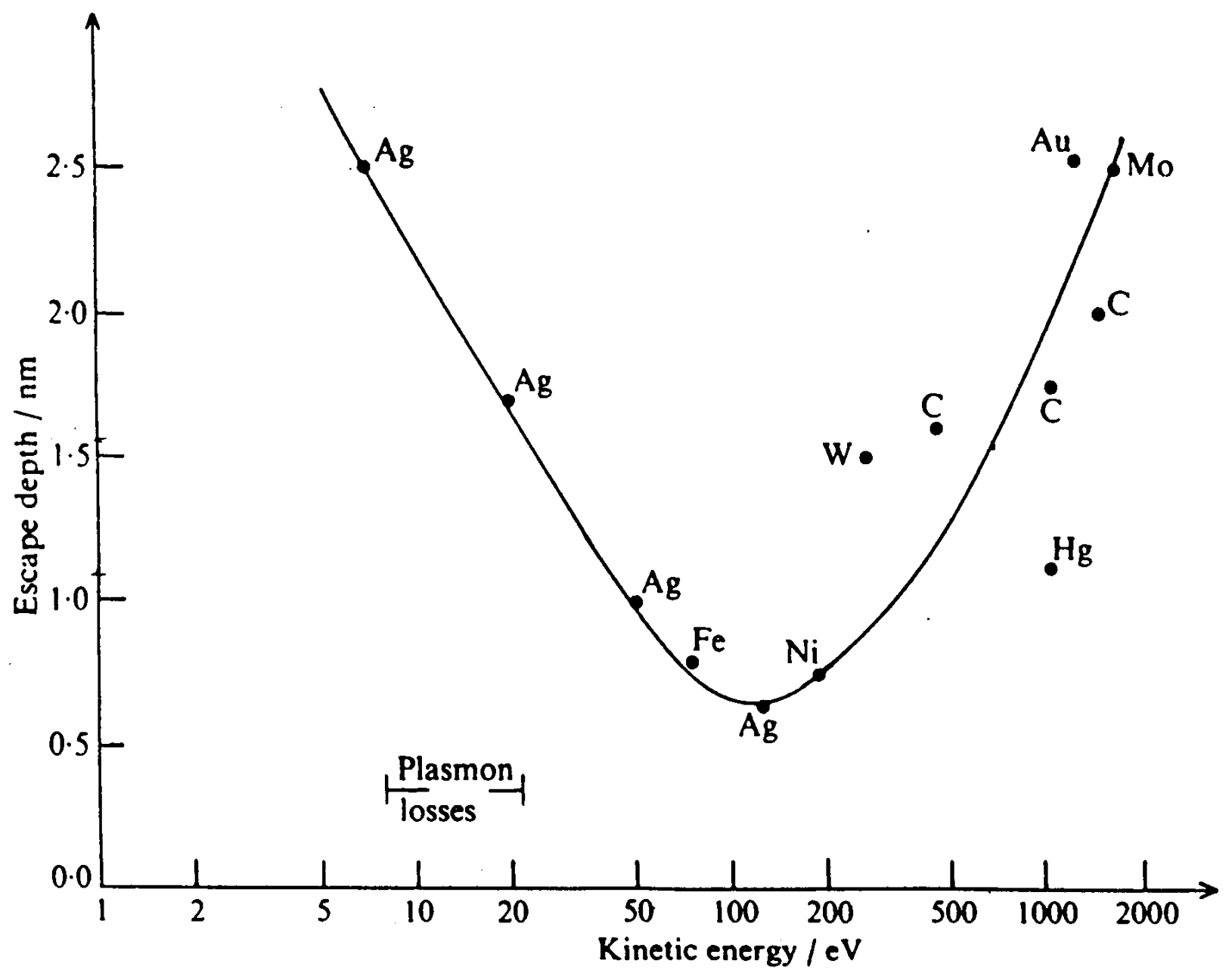

Figure 3.3 Electron mean free path vs. kinetic energy. [40] 
Here $I_{i}$ is the area under the curve, representative of the electron current due to the photoelectron process and $S_{i}$ is the atomic sensitivity factor of the species i.

To the extent possible, the sensitivity factors were determined rather than rely on those obtained by others. This was accomplished by performing XPS analysis of $\mathrm{Ar}^{+}$ion etched CdTe and ZnTe surfaces. It has been reported that $\mathrm{Ar}^{+}$ion etching produces a stoichiometric surface for CdTe [31]. Using this fact and the general equation 3.2, the sensitivity factors of $\mathrm{Cd}$ and $\mathrm{Zn}$ relative to $\mathrm{Te}$ can be determined. These results are described in the next chapter.

The XPS system used in the lab consists of a water-cooled dual-anode x-ray source along with a hemispherical electron energy analyzer. A Physical Electronics Industries (PHI) model 50-096 X-ray source with $\mathrm{Mg} \mathrm{K} \alpha(1253.6 \mathrm{eV})$ and Al K $\alpha$ (1486.6 $\mathrm{eV}$ ) as the two anode sources is used in the setup. Either of the two anode sources was operated at 300 Watts during XPS analysis. Emitted electrons were analyzed using a VG100AX hemispherical analyzer in 1:1 lens mode, resulting in a sampling area slightly more than $4 \mathrm{~mm}^{2}$ wide. The spectra were taken in a constant analyzer energy mode with $20 \mathrm{eV}$ pass energy. The spectrometer was calibrated using an argon etched silver foil. Data acquisition was performed with a VGX900 board and software. Data analysis was performed using Jandel Scientific "Peak fit" program.

\subsection{Mass Spectrometry}

Mass spectrometry was used to characterize the neutral and ionic species emitted from the sources. The main principles involved in mass spectrometry include ionization of the incoming neutral species, focussing the ions into the mass filter, mass separation and detection. In the present studies an Extranuclear Laboratories, Inc. Extrel quadrupole 
mass spectrometer with a mass filter, ionizer, and channeltron detector were used. Figure 3.4 shows a schematic of these key elements. The ionization process involves energy transfer from electrons produced by the filament to the neutral molecule (M). This energy transfer results in the ionization of the molecule by the ejection of one of its electrons and the resulting ion is called the parent ion $\left(\mathrm{M}^{+}\right)$. (The ejection of more than one electron is avoided by reducing the energy of the ionizing electrons). The parent ions, which still have considerable excess energy, may decompose further to produce daughter ions $\left(\mathrm{D}^{+}\right)$. Usually, the degree of decomposition can be controlled, by controlling the energy of the ionizing electrons.

The flux of electrons [41] and their energy are controlled by fixing the emission current and the energy to which these electrons are accelerated. This is accomplished with the filament and the electron energy power supplies as shown in Figure 3.5. The energy of the ionizing electrons may be varied smoothly from $+3 \mathrm{~V}$ to $+100 \mathrm{~V}$ about the circuit common voltage, which is determined by the "ion energy" power supply.

The ions that are formed are focussed into a well-defined beam by a series of electrostatic lenses (ion optics in Figure 3.4, extractor and lenses 1,2,3 in Figure 3.5). Because of the conservative nature of the electrostatic fields the kinetic energy of the ions will be established by the voltage on the ion energy power supply $( \pm 50 \mathrm{~V}$ relative to ground). The setting of the ion energy power supply determines the energy of the singly charged ions entering the mass filter through the grounded entrance.

As illustrated in Figure 3.4 the next task is to mass separate or analyze all of the ions according to their mass to change ratio. This is accomplished using a quadrupole mass filter constructed ideally of four electrically conducting rods (parallel hyperbolic 
cylindrical surfaces in case of the Extrel mass spectrometer). The opposite electrodes of the filter are connected together, and to one pair is applied a potential

$$
f(t)=U+V \cos (2 \pi f t)
$$

where $\mathrm{U}$ is a dc voltage and $\mathrm{V}$ is the amplitude of a radio frequency (rf) voltage at the frequency $\mathrm{f}$. To the other pair of electrodes the same potential, but opposite sign is applied. If an ion is injected at the end of this assembly with motion generally parallel to the z-axis (length), the rf and dc fields which are perpendicular to the $\mathrm{z}$-axis will cause it undergo transverse motion in he $\mathrm{x}-\mathrm{y}$ plane. With proper selection of $\mathrm{U}$ and $\mathrm{V}$, ions of a given $\mathrm{m} / \mathrm{z}$, where $\mathrm{m}$ is the mass of the ion and $\mathrm{z}$ is the number of electrostatic charge units (e) carried by the ion, will have stable trajectories; i.e., the ions will oscillate about the z-axis and ultimately emerge from the opposite end of the mass filter assembly. Ions with other values of $\mathrm{m} / \mathrm{z}$ will have unstable trajectories and they will move away from the z-axis and ultimately strike the electrodes, thus being removed.

The final task is to detect the various ions. This is accomplished by an electron multiplier (e.g., channel plates, channeltron or conversion dynodes). The electron multiplier is a device which when struck by an ion, electron or photon will generate a short pulse of secondary electrons. An operating voltage is applied along the length of the multiplier so that these secondary electrons be attracted towards the anode. As the electrons move towards the anode, they strike the second and higher stages and generate more electrons, creating an avalanche effect, which is responsible for the multiplication action. Gains of $10^{6}$ and greater are common. 


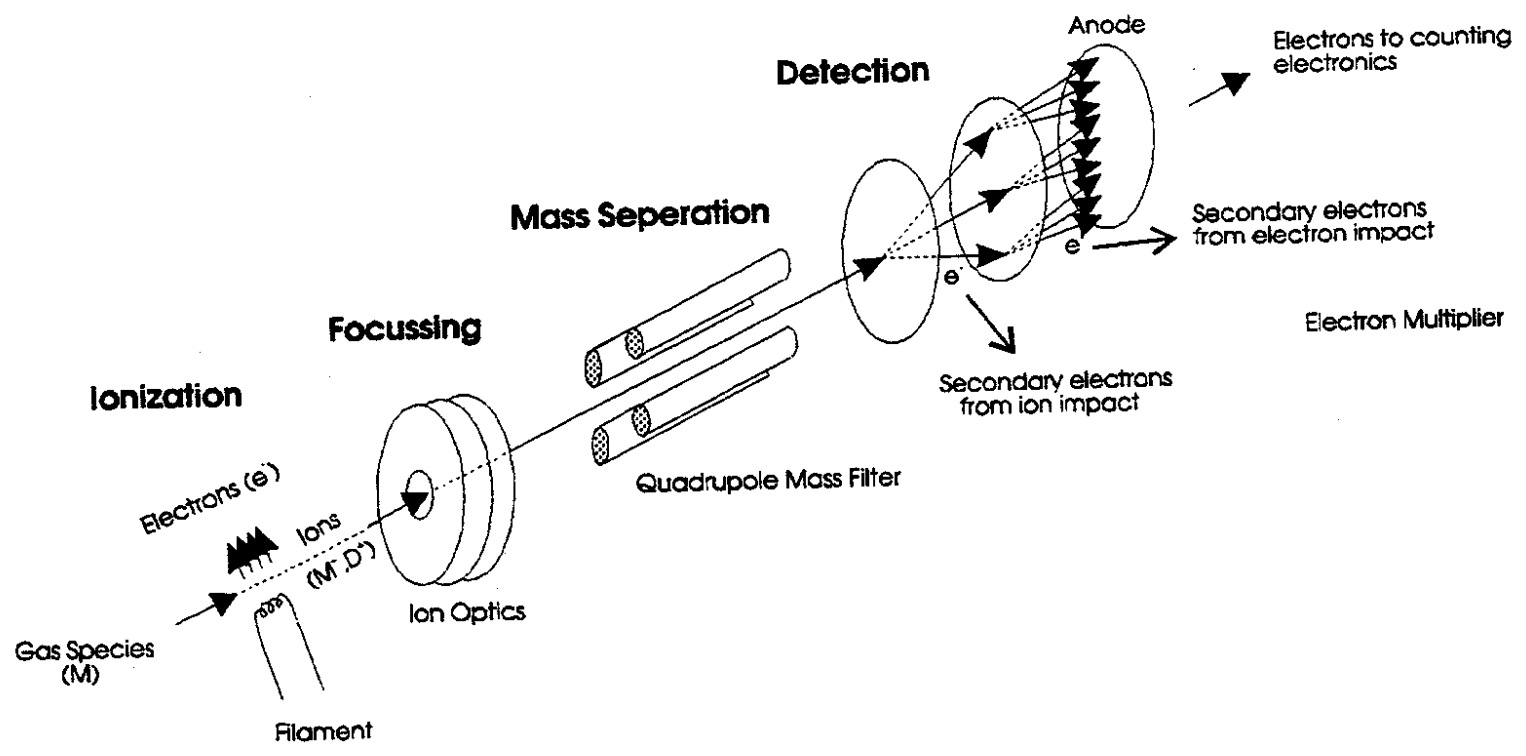

Figure 3.4 Key elements of quadrupole mass spectrometer. [42] 


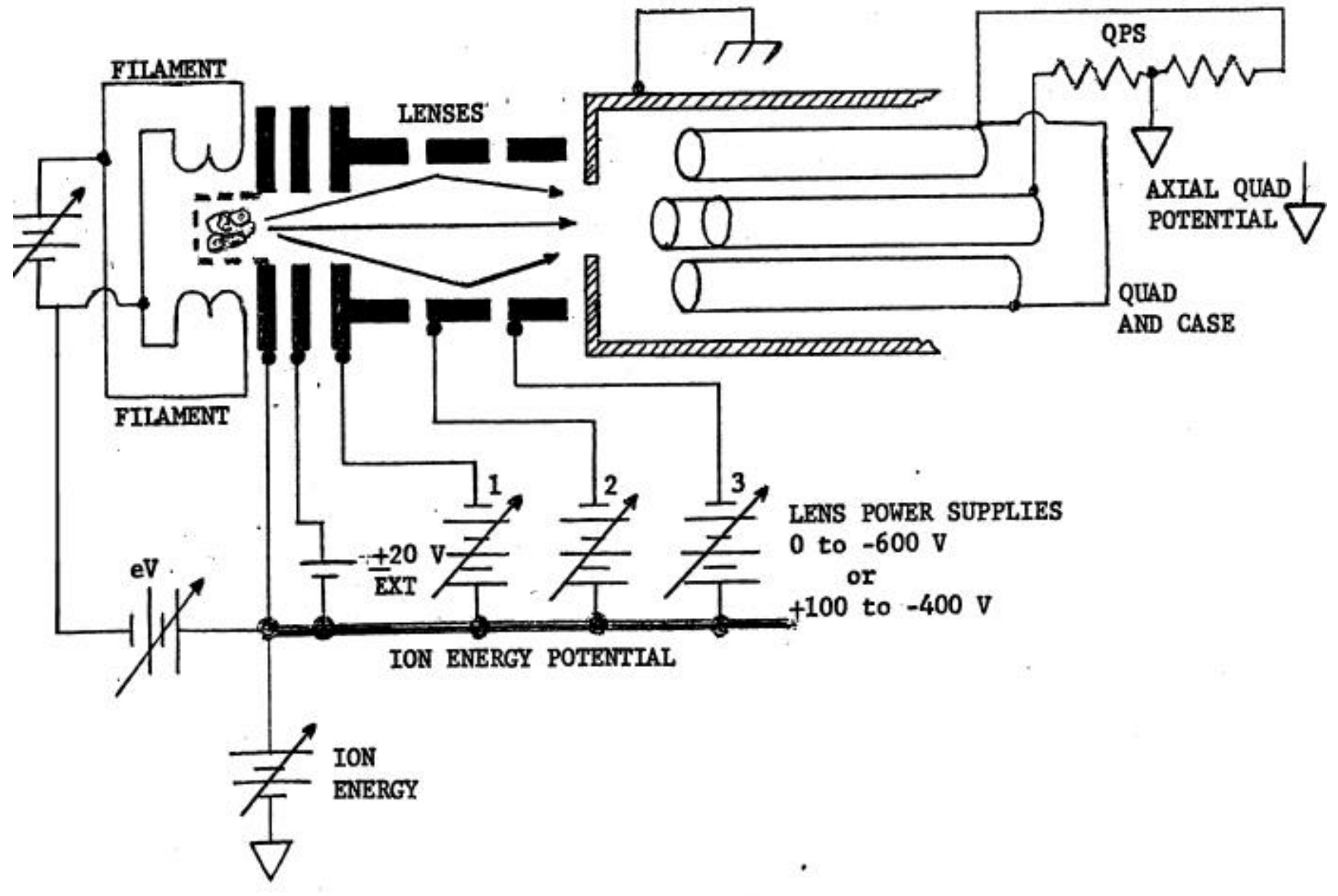

Figure 3.5 Ionizer control of the Extrel mass spectrometer. [41] 


\section{Results and Discussion}

\subsection{Mass Spectrometric Characterization of the Hydrogen plasma}

The mass spectrometric characterization of the neutral \& ionic species produced by the Oxford source was performed for two different apertures. These are identified in Table 4.1 shown below.

\begin{tabular}{|c|c|c|}
\cline { 2 - 3 } \multicolumn{1}{c|}{} & Number of Holes & Diameter $(\mathrm{mm})$ \\
\hline Aperture 1 & 9 & 0.2 \\
\hline Aperture 2 & 1 & 0.6 \\
\hline
\end{tabular}

Table 4.1 Different apertures used with the plasma source

The open area of the single hole aperture was chosen to equal that of the nine hole aperture.

After the plasma was ignited, the power was set to the desired level, the $\mathrm{H}_{2}$ and $\mathrm{Ar}$ flow rates were adjusted to provide the desired gas composition, and the pressure in the system was set to the desired level by adjusting the flow rates and/or the precision leak valve. At this point, the mass spectrometer was used to characterize the $\mathrm{H}^{+}, \mathrm{H}_{2}{ }^{+}, \mathrm{H}$ and $\mathrm{H}_{2}$ species produced by the source.

In the mass spectrometer measurements, $\mathrm{H}^{+}$formed in the source and $\mathrm{H}^{+}$formed in the mass spectrometer ionizer by ionizing $\mathrm{H}$ atoms produced either in the source or by cracking $\mathrm{H}_{2}$ in the ionizer will appear at $\mathrm{m} / \mathrm{z}=1$ ( $\mathrm{m}$ is the mass number of a given ion, $\mathrm{z}$ is the charge carried by the ion). Similarly $\mathrm{H}_{2}{ }^{+}$formed in the source and $\mathrm{H}_{2}{ }^{+}$formed by the ionization of $\mathrm{H}_{2}$ in the ionizer appear at $\mathrm{m} / \mathrm{z}=2$. To minimize cracking of $\mathrm{H}_{2}$, the mass spec analyses were performed using ionizing electrons with energy of $20 \mathrm{eV}$. This electron energy is just below the threshold for cracking $\mathrm{H}_{2}$ but is sufficient to ionize $\mathrm{H}$ 
and $\mathrm{H}_{2}$. To discriminate between the species ionized in the source and the neutral species ionized in the ionizer and to determine the energy distribution of the ionic species, measurements of the peak intensity of $\mathrm{m} / \mathrm{z}=1 \& 2$ were performed as a function of ion energy. This energy is determined by the value of the voltage (V) applied to the plate A (see Figure 3.4) and the wire mesh defining the ionizing volume. When a positive voltage $\mathrm{V}$ is applied to this plate, the ions formed in the plasma source and having energy $\mathrm{V} \mathrm{eV}$ and lower are rejected (will not enter the ionizer). Further, at sufficiently high ion energy, virtually all ions will be rejected, and the mass spectrometer signal will be mainly due to neutrals ionized in the ionizer. Thus, the signal at higher voltages should be due to neutrals $\left(\mathrm{H}\right.$ and $\left.\mathrm{H}_{2}\right)$ emanating from the source while the signal at lower voltages should be due to a combination of neutrals ionized in the source and ions formed in the source.

To further discriminate between ions formed in the source and those formed in the ionizer, the above measurements of signal intensity versus ion energy were performed under two distinctly different electron emission modes:

\begin{tabular}{|c|c|}
\hline Emission mode & Emission current (mA) \\
\hline Low & 0.018 \\
\hline High & 1.000 \\
\hline
\end{tabular}

\section{Table 4.2 Different modes of operation of a mass spectrometer}

The signal in the low emission mode should be primarily due to the ions formed in the plasma source. The signal in the high emission mode should be due to the ions formed in the source and the neutrals ionized in the ionizer. The results of such measurements are shown in Figures 4.1 \& 4.2 for the a single hole aperture, an rf-power of $500 \mathrm{~W}$, a chamber pressure of $7.2 \times 10^{-5}$ Torr, and a 2:1 $\mathrm{H}_{2}$ : Ar flow. 


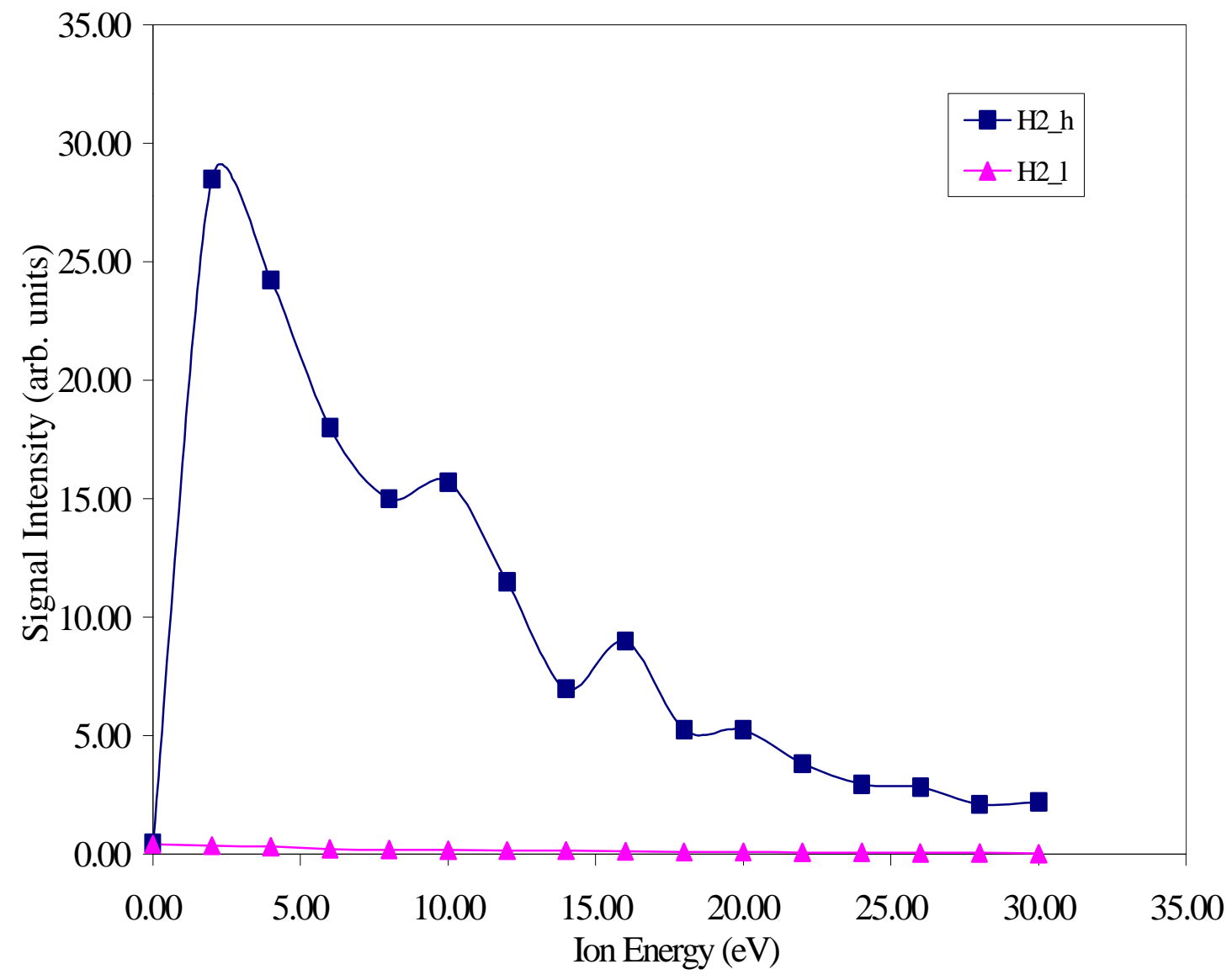

Figure 4.1 Signal intensity vs. ion energy for the single hole aperture using the low $\left(\mathrm{H}_{2} \mathrm{l}\right)$ and high $\left(\mathrm{H}_{2} \mathrm{~h}\right)$ emission modes. The operating conditions were: power $=500 \mathrm{~W}$, pressure $=7.2 \times 10^{-5}$ Torr and $66.7 \% \mathrm{H}_{2}$ flow. 


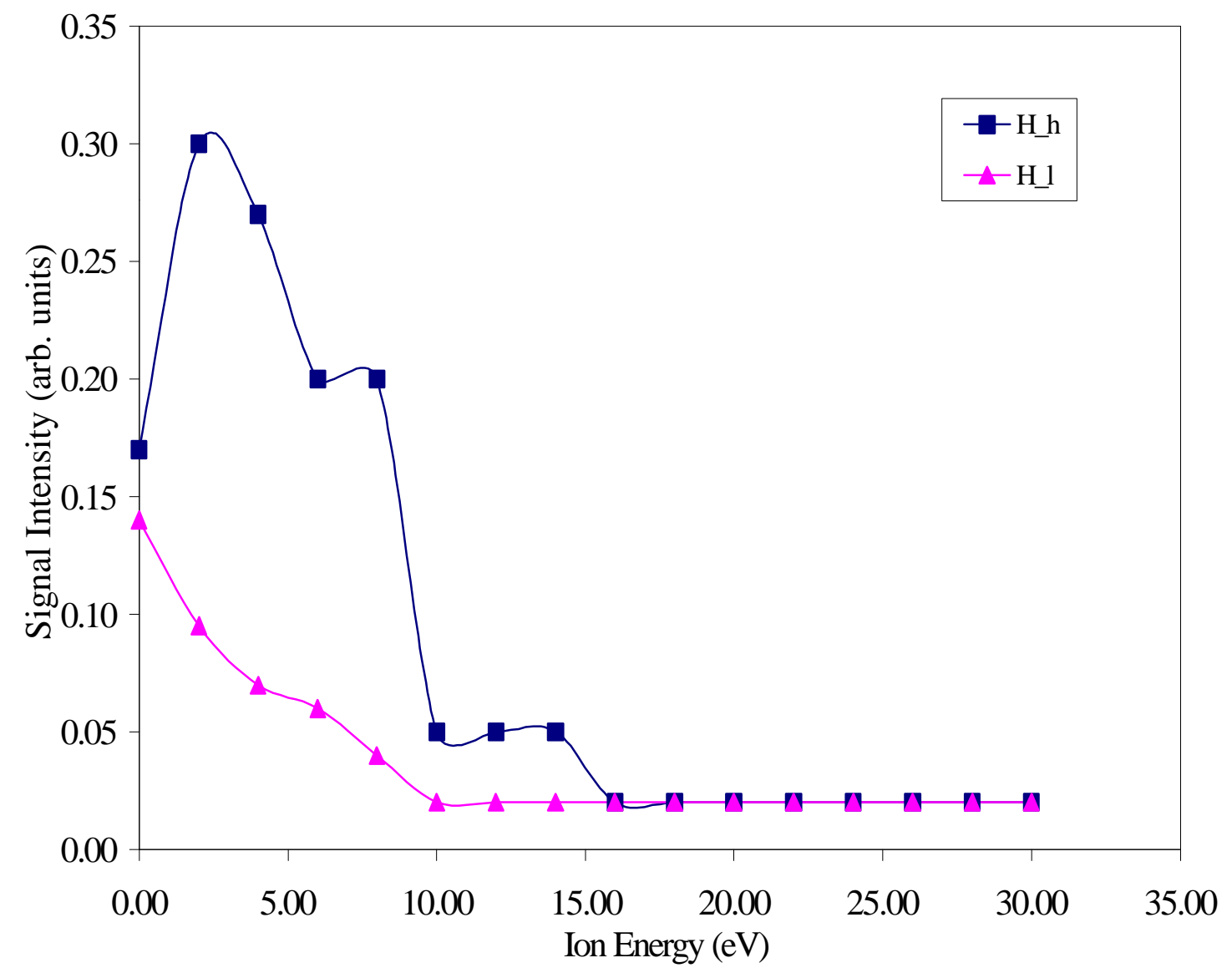

Figure 4.2 Signal intensity vs. ion energy for the single hole aperture using the low (H_l) and high (H_h) emission modes. The operating conditions were: power $=500 \mathrm{~W}$, pressure $=7.2 \times 10^{-5}$ Torr and $66.7 \% \mathrm{H}_{2}$ flow. 
The curves designated as $\mathrm{H}_{-} 1$ and $\mathrm{H}_{2} \_1$ represent data taken in the low emission mode for $\mathrm{m} / \mathrm{z}=1$ and 2 , respectively. The corresponding curves, $\mathrm{H} \_\mathrm{h}$ and $\mathrm{H}_{2} \_\mathrm{h}$, represent the data for the high emission mode. Notice that for $\mathrm{H}_{2}$ h , the combined signal due to ions and neutrals emanating from the source, is much greater than $\mathrm{H}_{2} \_$, the signal due to ions only. For $\mathrm{H}$-atoms this is not true, the $\mathrm{H} \_\mathrm{h}$ and $\mathrm{H} \_1$ are comparable in scale. Comparing $\mathrm{H}_{2}$ to $\mathrm{H}$, it is also evident that $\mathrm{H}_{2}$ (ion or neutral) species are dominant.

\subsubsection{Mass Filter Transmission Function}

From the data in Figures 4.1 and 4.2, respectively, the signal due to $\mathrm{H}_{2}$ and $\mathrm{H}$ neutrals emanating from the source and ionized in the ionizer can be determined by subtracting the low emission mode data from the high emission data. The results for such a calculation will indicate that the mass spec signal intensity due to neutral species is ion energy dependent. This is at first surprising since the flux of neutrals emanating from the source must be a constant (for a given set of operating conditions) independent of ion energy. The reason for the apparent energy dependence is that the transmission efficiency of the quadrupole mass filter is a function of the ion energy as established by the ion energy power supply. In experiments to establish the transmission function, the plasma source was turned off, the ionizer electron emission current was set for $1.000 \mathrm{~mA}$, and the electron energy was set for $20 \mathrm{eV}$. Then signal intensity for $\mathrm{m} / \mathrm{z}=2$ was measured as a function of ion energy. The results for these measurements are shown in Figure 4.3. The data are normalized using the maximum intensity observed.

The form of the transmission function can be understood in terms of the basic characteristics of the quadrupole mass filter. The mass filter separates ions according to their $\mathrm{m} / \mathrm{z}$ values, and it requires that the ions have fairly narrow range of velocities or 


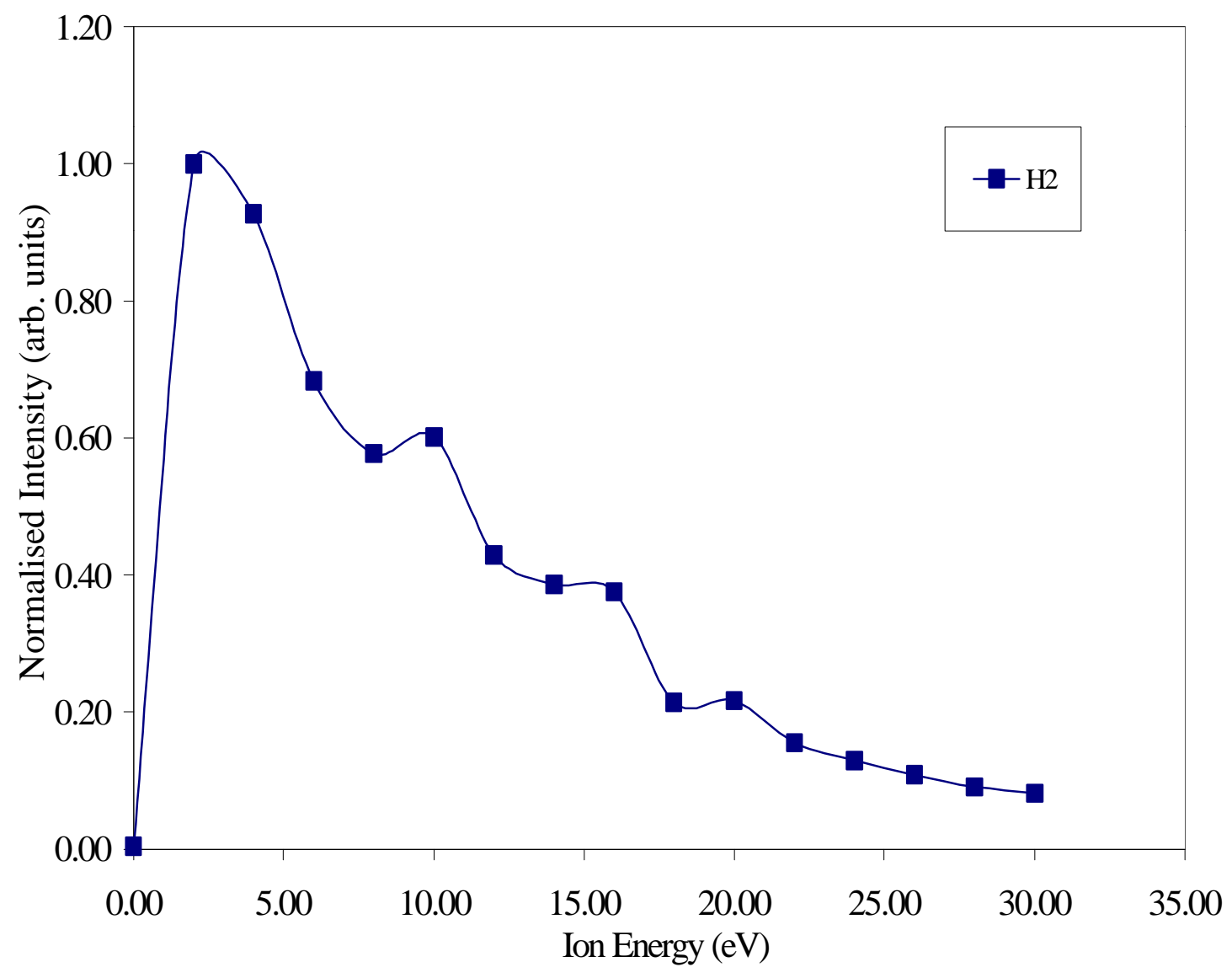

Figure 4.3 Mass filter transmission function of $\mathrm{H}_{2}$ for the single-hole aperture. 
kinetic energies. This requirement exists because an ion, while in the mass filter, must see a sufficient number of oscillations of the RF field in order to know whether it is supposed to be rejected or transmitted. If the ion is travelling too fast, it does not see sufficient number of oscillations and thus can be transmitted when it should be rejected and vice versa. Thus, there is a optimum kinetic energy one would like the ion to have and this is only a few $\mathrm{eV}$; the actual number depends on the filter geometry, the mass of the ion and the desired mass resolution. If the kinetic energy is too large, the most serious effect is that an ion is transmitted and appears at an $\mathrm{m} / \mathrm{z}$ position less than the true $\mathrm{m} / \mathrm{z}$. Thus a given $\mathrm{m} / \mathrm{z}$ peak may develop a shoulder as the low $\mathrm{m} / \mathrm{z}$ side.

Figures $4.4 \& 4.5$ show plots of the experimentally derived neutral signals (i.e. due to ions formed in the ionizer) for $\mathrm{m} / \mathrm{z}=1$ and 2 (H_c \& $\mathrm{H}_{2} \_\mathrm{c}$, respectively) fitted to the measured transmission function. Agreement is clearly better for the $\mathrm{H}_{2}$ neutrals, but given the low signal intensity for H-neutrals, the fit is acceptable for both.

\subsubsection{Beam composition and Ion Energy Distribution}

Given the signal intensities for the hydrogen neutrals $\left(\mathrm{H} \_c\right.$ \& $\mathrm{H}_{2} \_$c) and ions $\left(\mathrm{H}_{-} 1\right.$ \& $\mathrm{H}_{2} \_$l), the composition of the beam produced by the Oxford-rf plasma source can be determined. The actual number densities of $\mathrm{H}^{+}, \mathrm{H}_{2}{ }^{+}, \mathrm{H}$ and $\mathrm{H}_{2}$ species, i.e., $\mathrm{N} \_\mathrm{H}+, \mathrm{N} \_\mathrm{H} 2+$, $\mathrm{N}_{-} \mathrm{H}$ and $\mathrm{N}_{-} \mathrm{H} 2$, respectively, at the aperture to the mass spec are related to the corresponding mass spec signal intensities by the following equations

$$
\begin{aligned}
& H_{-} l(\xi)=Y \lim _{n \rightarrow \infty} \sum_{i=0}^{n} T\left(\xi+\Delta \xi_{i}\right) N_{-H^{+}}\left(\xi+\Delta \xi_{i}\right) \quad\left(\Delta \xi_{\mathrm{i}}=\mathrm{i} \Delta \xi\right) \\
& H_{2-} l(\xi)=Y \lim _{n \rightarrow \infty} \sum_{i=0}^{n} T\left(\xi+\Delta \xi_{i}\right) N_{-H_{2}^{+}}\left(\xi+\Delta \xi_{i}\right)
\end{aligned}
$$




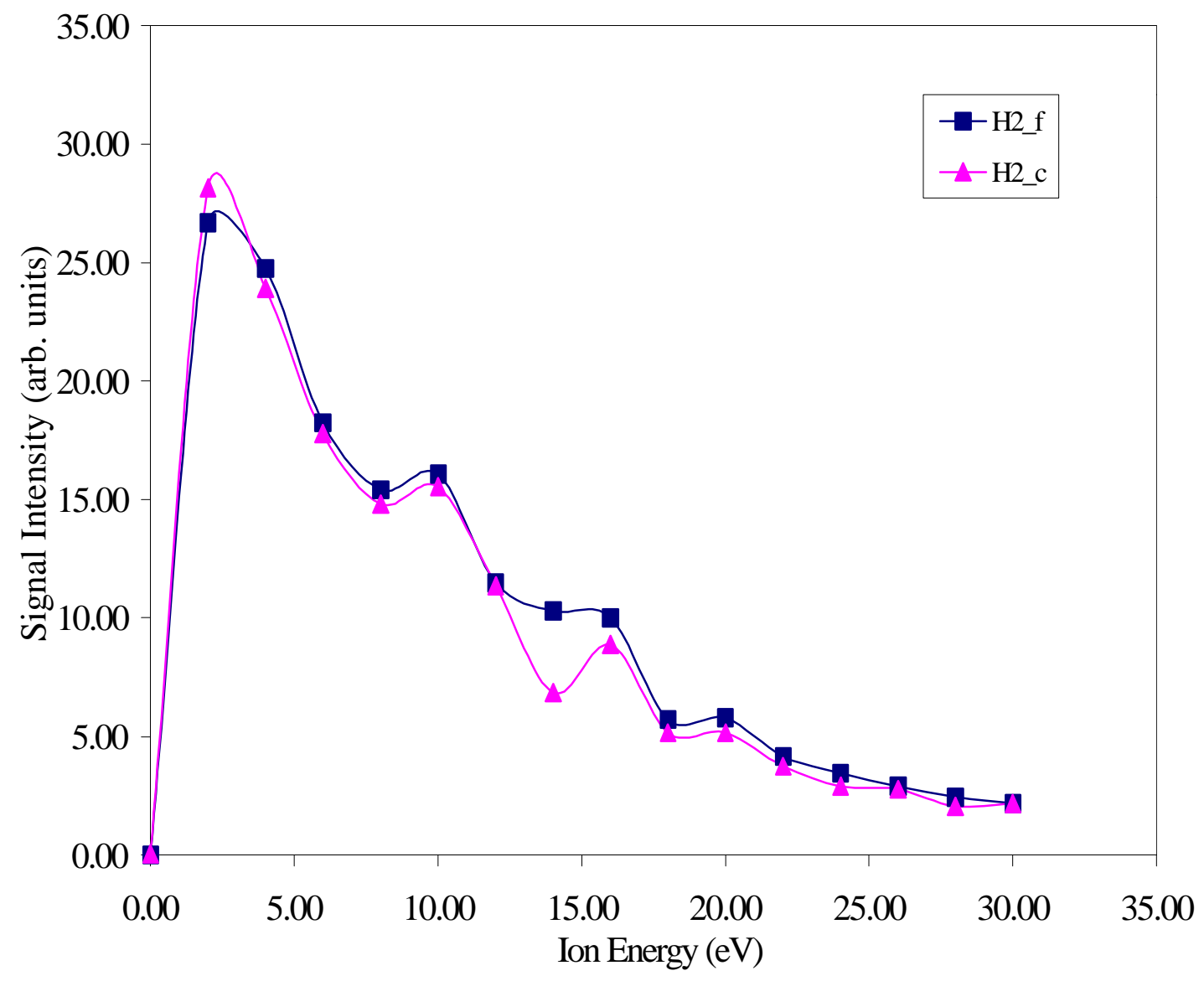

Figure 4.4 Neutral signal intensity vs. ion energy for the single hole aperture showing the calculated $\left(\mathrm{H}_{2 \_} \mathrm{c}\right)$ and fitted $\left(\mathrm{H}_{2} \mathrm{f}\right)$ curves. The operating conditions were: power $=500 \mathrm{~W}$, pressure $=7.2 \times 10^{-5}$ Torr and $66.7 \% \mathrm{H}_{2}$ flow. 


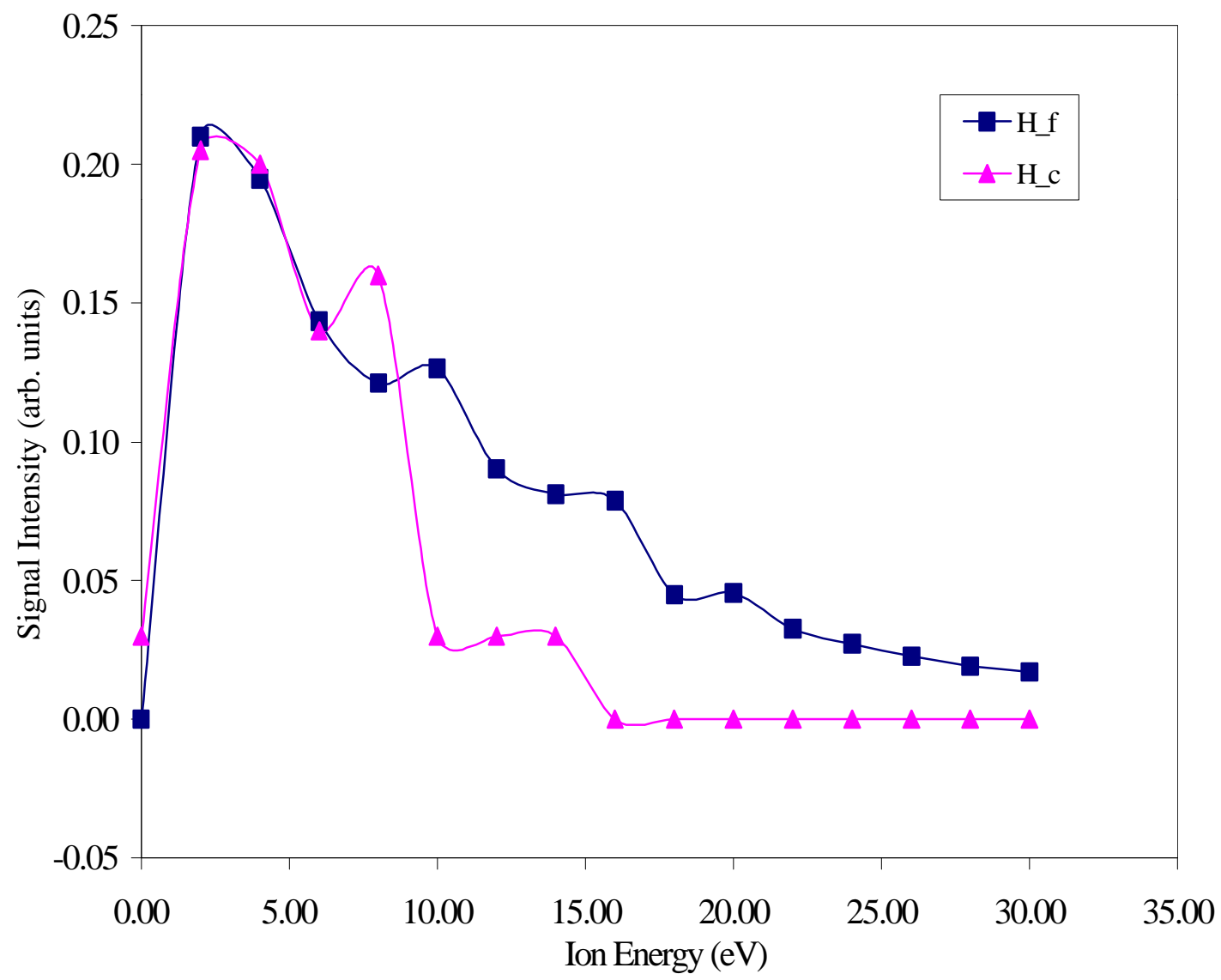

Figure 4.5 Neutral signal intensity vs. ion energy for the single hole aperture showing the calculated (H_c) and fitted (H_f) curves. The operating conditions were: power $=500 \mathrm{~W}$, pressure $=7.2 \times 10^{-5}$ Torr and $66.7 \% \mathrm{H}_{2}$ flow. 


$$
\begin{aligned}
& H_{-} c(\xi)=Y T(\xi) N_{-^{H}}(\xi) E_{H} \\
& H_{2-} c(\xi)=Y T(\xi) N_{-^{H}}(\xi) E_{H_{2}}
\end{aligned}
$$

Here, $\mathrm{Y}$ is a proportionality constant relating the actual ion current (from the ionizer or source) to the electron current produced by the channeltron in the mass spec detector, $\mathrm{T}(\xi)$ is the transmission function at an ion energy $\xi$, and $E_{H}, E_{H_{2}}$ are the ionization fractions for $\mathrm{H}$ and $\mathrm{H}_{2}$ respectively. The quantity $\Delta \xi$ is a small increment in energy. The smaller this value, the more accurate the expressions for $\mathrm{H}_{-} 1$ and $\mathrm{H}_{2} \_$l.

Equations 4.1, 4.2 are based on the fact that the ions formed outside the ionization volume (i.e., in the plasma source) will enter the mass filter with their energy, $\xi$, unaltered as long as $\xi$ is greater than the set value of ion energy. Further these ions with energy $\xi$ will be transmitted with an efficiency of $\mathrm{T}(\xi)$. Equations 4.3, 4.4 are based on the fact that the neutrals, which are ionized in the ionizer, all have the same ion energy, $\xi$, and be transmitted with an efficiency $\mathrm{T}(\xi)$.

The ionization fractions enter the expressions for $\mathrm{H}_{-} \mathrm{c}$ and $\mathrm{H}_{2} \_\mathrm{c}$ since every ion produced by the source is counted by the mass spec, but only a certain fraction of the neutrals are ionized. The ionization fraction can be determined by introducing a known flux of $\mathrm{H}_{2}$ gas into the ionizer and then measuring the corresponding signal directly using a Faraday plate detector (i.e. without an electron multiplier). From these measurements, the ionization fraction for $\mathrm{H}_{2}$ can be obtained. For our system, one $\mathrm{H}_{2}$ in $3.5 \times 10^{6}$ was ionized for an electron energy of $20 \mathrm{eV}$ and a filament current of $1 \mathrm{~mA}$. We assume an equivalent ionization fraction for $\mathrm{H}$. Based on these equations, the products $\mathrm{Y}^{*} \mathrm{~N}_{-} \mathrm{H}+$, $\mathrm{Y} * \mathrm{~N} \_\mathrm{H} 2+, \mathrm{Y} * \mathrm{~N} \_\mathrm{H}$, and $\mathrm{Y} * \mathrm{~N} \_\mathrm{H} 2$ were calculated and plotted as shown in Figure 4.6. Note 


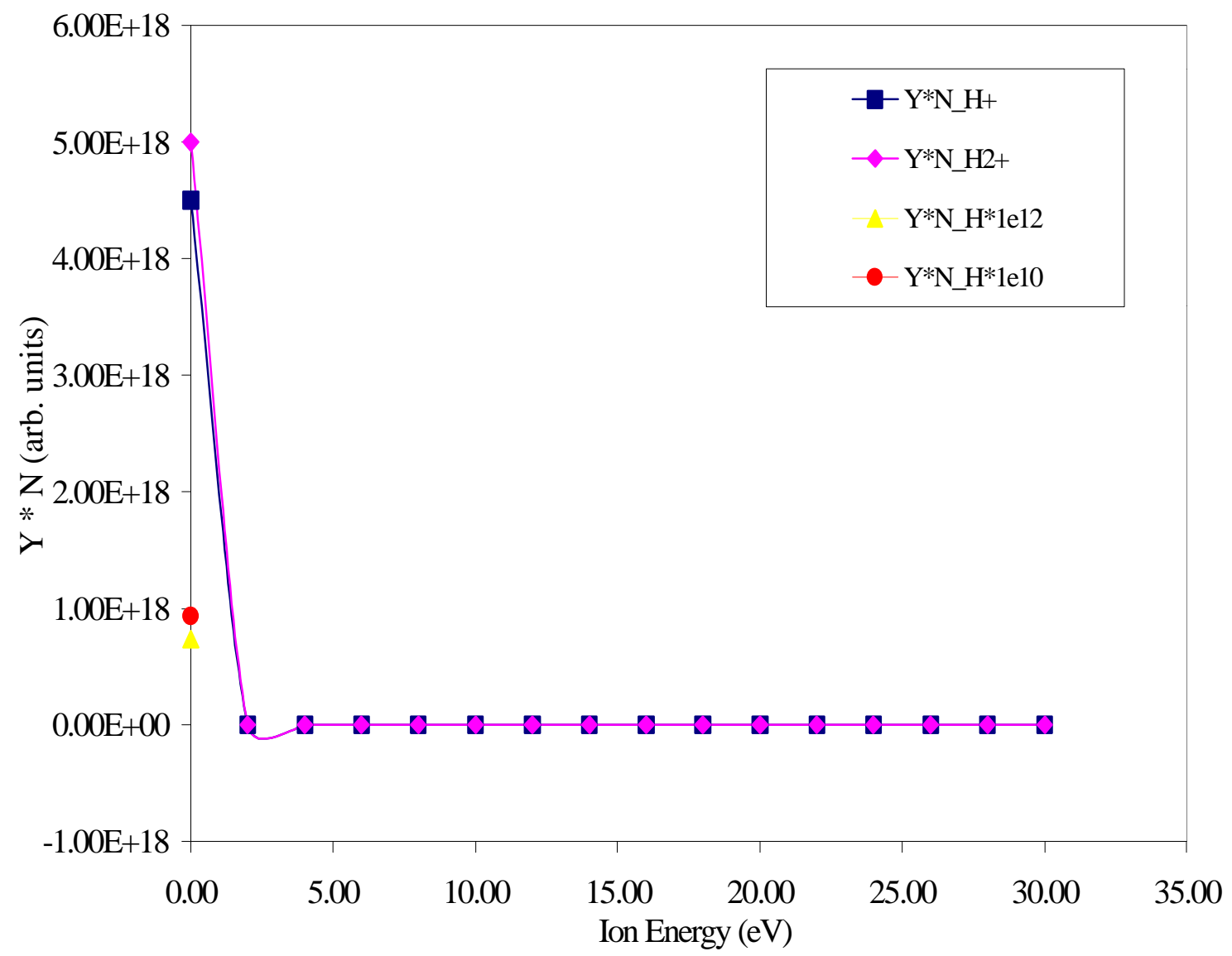

Figure 4.6 $\mathrm{Y}^{*} \mathrm{~N}$ vs. ion energy for a single hole aperture. The operating conditions were: power $=500 \mathrm{~W}$, pressure $=$ $7.2 \times 10^{-5}$ Torr and $66.7 \% \mathrm{H}_{2}$ flow. 
the scale factors for neutral species which are plotted at an ion energy of zero (i.e. a low kinetic energy corresponding to room temperature). It is clear that low energy ions dominate the beam with nearly equal level of low energy $\mathrm{H}^{+}$and $\mathrm{H}_{2}{ }^{+}$. The composition of the beam for this particular set of operating conditions were $7 \% \mathrm{H}, 8 \% \mathrm{H}_{2}, 40 \% \mathrm{H}^{+}$, and $45 \% \mathrm{H}_{2}^{+}$.

\subsubsection{The Effects of Process Parameters on Ion Content}

Since ions are the dominant species, a series of experiments was performed to determine the effects of the various process parameters on ion content. To this end, the effect of RF-power, chamber pressure and gas composition on the hydrogen plasma was studied for both the single and the nine hole apertures. To facilitate these measurements, a third ion detection mode was utilized. In this case, the ionizer was turned completely off so only ions produced in the plasma source could be detected.

The effect of rf-power for each aperture was studied keeping the pressure and composition constant. Figure 4.7 shows the plot of intensity versus rf power for the nine hole aperture at a chamber pressure $=5.9 \times 10^{-5}$ Torr and $66.7 \% \mathrm{H}_{2}$. The above figure indicates that the $\mathrm{H}^{+}$ions marginally decrease with increasing rf-power, while the $\mathrm{H}_{2}{ }^{+}$ ions increase with increasing rf-power. The dominant ions in this case are the $\mathrm{H}^{+}$ions.

Figure 4.8 shows a plot of intensity versus rf-power for the single hole aperture at a chamber pressure $=5.1 \times 10^{-5}$ Torr and $76.9 \%$. These data indicate that the ion levels for the single hole aperture are significantly greater than for the 9 hole aperture. This is consistent with previous studies by Kumar [42] for nitrogen plasma generated by the rfsource. As seen in Figure 4.8, the intensity of the $\mathrm{H}_{2}{ }^{+}$ions increases as the rf-power increases and saturates at a power of around $400 \mathrm{~W}$. The intensity of the $\mathrm{H}^{+}$ions remains 


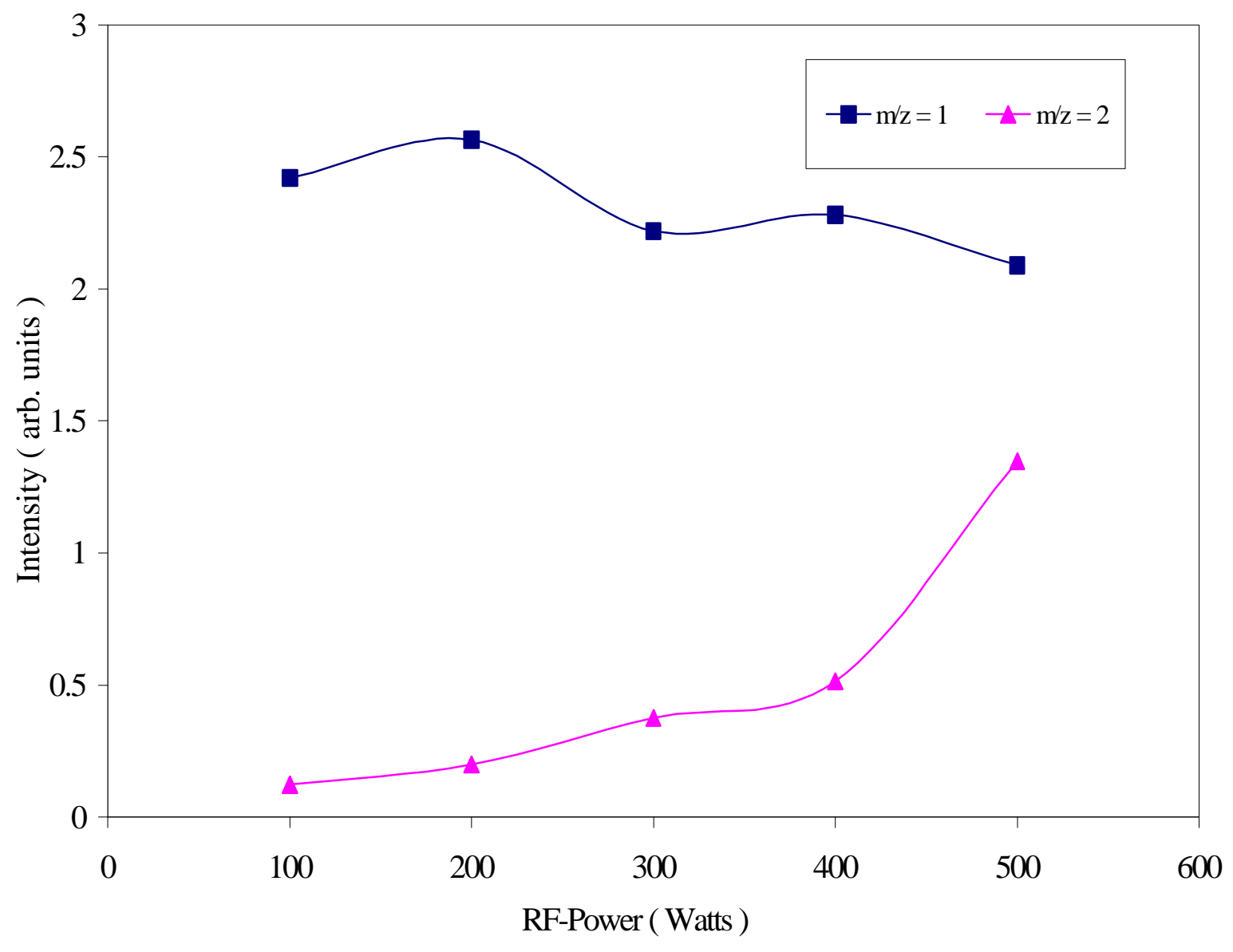

Figure 4.7 Effect of rf-power on ion content for the 9-hole aperture. The operating conditions were: pressure $=5.9 \times 10^{-5}$ Torr and $66.7 \% \mathrm{H}_{2}$ flow. 


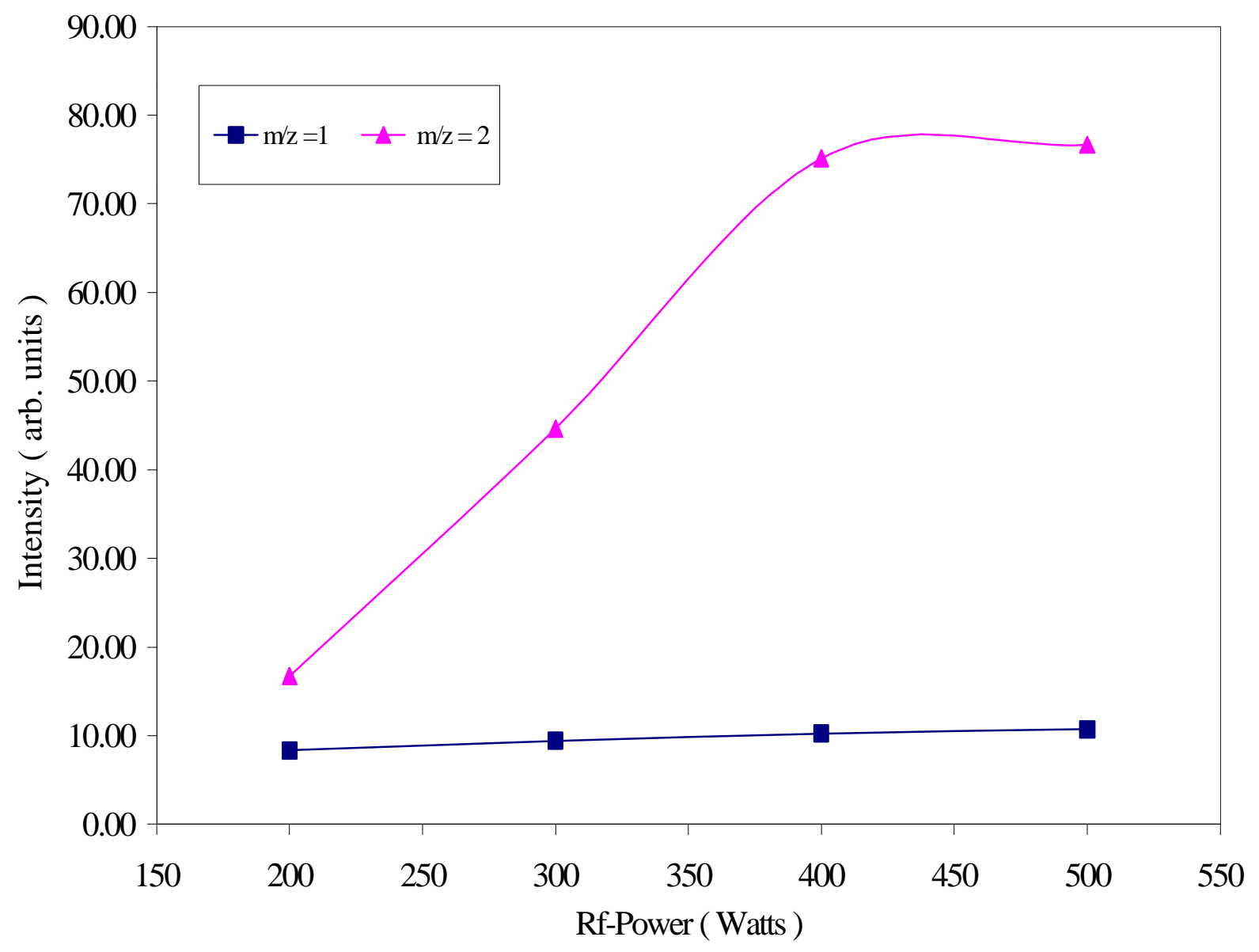

Figure 4.8 Effect of rf-power on ion content for the single-hole aperture. The operating conditions were: pressure $=5.1 \times 10^{-5}$ Torr and $76.9 \% \mathrm{H}_{2}$ flow. 
constant throughout. The dominant ions in this case are clearly the $\mathrm{H}_{2}{ }^{+}$ions.

The effect of chamber pressure was studied keeping the rf-power and flow rate constant. Figure 4.9 shows the plot of intensity versus chamber pressure for the nine hole aperture at a rf-power $=300 \mathrm{~W}$ and $66.7 \% \mathrm{H}_{2}$. This figure shows the $\mathrm{H}^{+}$ion content is more sensitive to pressures than that of $\mathrm{H}_{2}{ }^{+}$. Figure 4.10 shows the corresponding plot for the single hole aperture at a rf-power $=300 \mathrm{~W}$ and $66.7 \% \mathrm{H}_{2}$. For this case the $\mathrm{H}_{2}{ }^{+}$ions increases with pressure and reaches a maximum at $6 \times 10^{-5}$ Torr, after which it saturates. The $\mathrm{H}^{+}$ions remain nearly constant throughout. The dominant ions in this case are the $\mathrm{H}_{2}{ }^{+}$ions.

The effect of flow rate on the hydrogen plasma was studied keeping the rf-power and chamber pressure constant. Figure 4.11 shows a plot of intensity versus hydrogen content for the nine hole aperture at rf-power $=300 \mathrm{~W}$ and chamber pressure $=5.8 \times 10^{-5}$ Torr. This figure indicates that the $\mathrm{H}^{+}$ion intensity increases with hydrogen concentration in the argon-hydrogen mixture. The $\mathrm{H}_{2}{ }^{+}$ion intensities remain nearly constant throughout. The dominant species in this case are the $\mathrm{H}^{+}$ions. The effect of flow rate on the hydrogen plasma as studied for a single hole aperture is the same except that the dominant species would be $\mathrm{H}_{2}{ }^{+}$.

A series of mass spec scans were taken with the plasma on and the ionizer off to determine if $\mathrm{Ar}^{+}$ions emanated from the source. No trace of $\mathrm{Ar}^{+}$ions was observed for the nine-hole aperture. Although these experiments were not carried out for the single hole aperture, The results from the nine-hole aperture clearly showed that the plasma constituted mainly of hydrogen ions. 


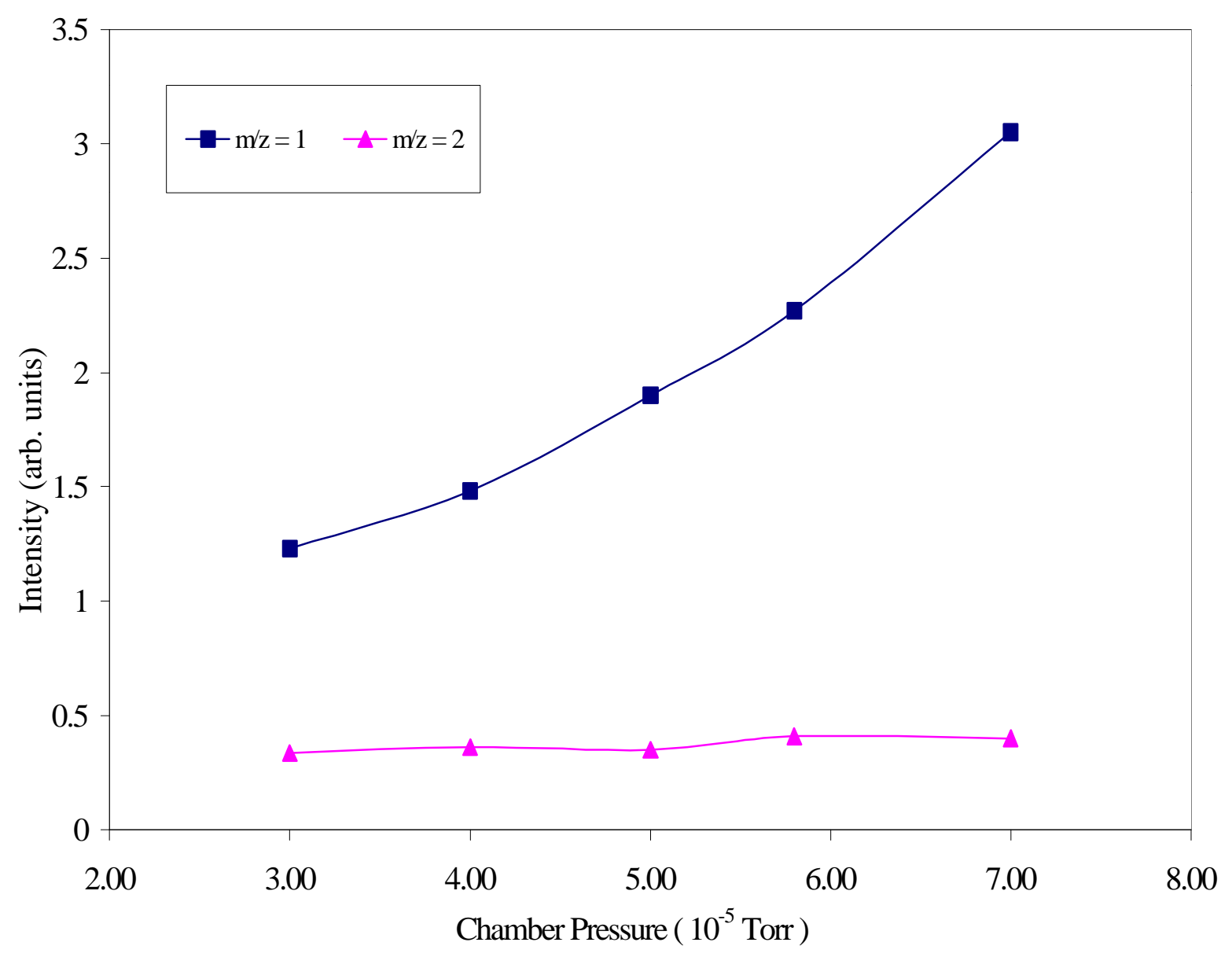

Figure 4.9 Effect of pressure on ion content for the nine-hole aperture. The operating conditions were: power $=300 \mathrm{~W}$ and $66.7 \% \mathrm{H}_{2}$ flow. 


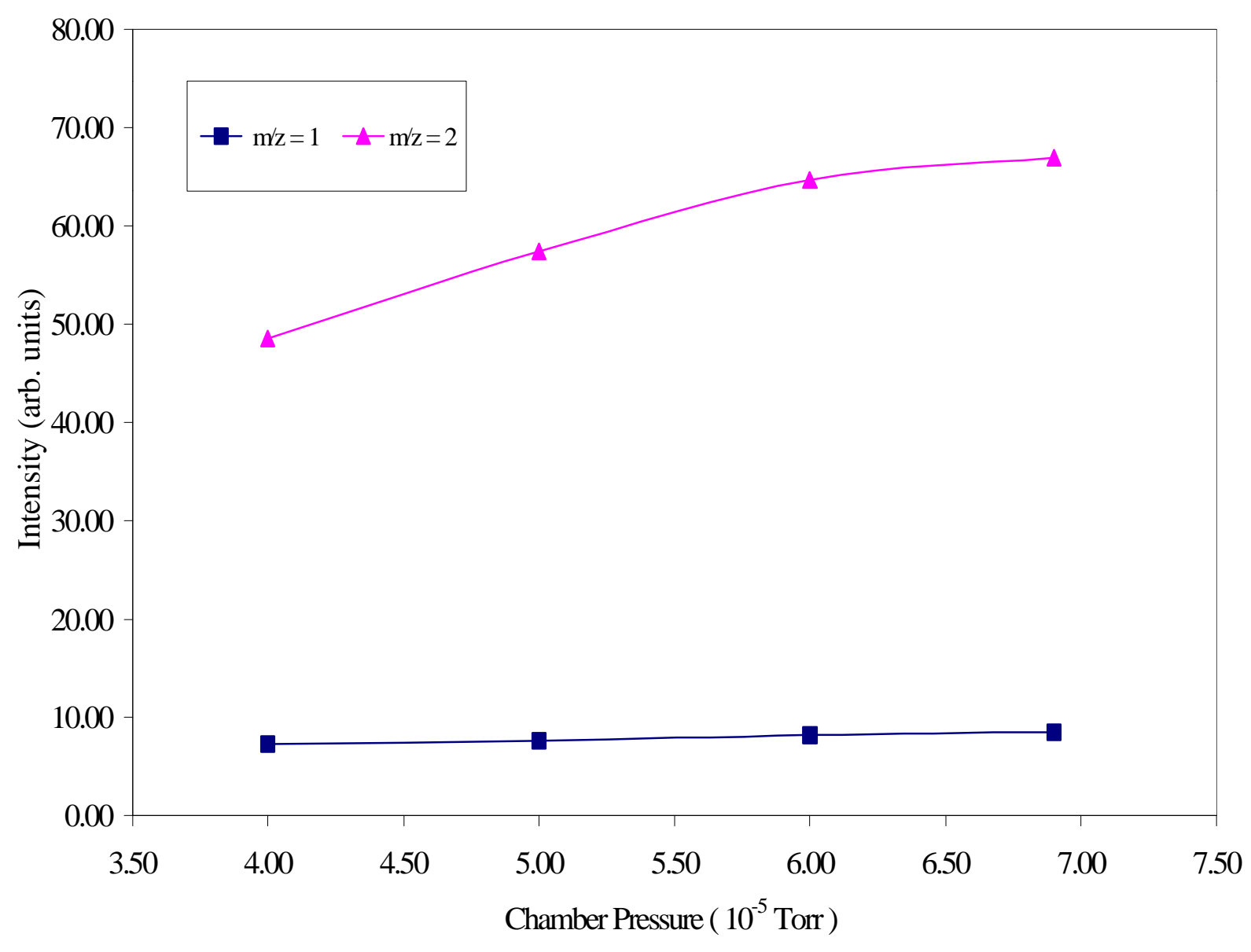

Figure 4.10 Effect of pressure on ion content for the single-hole aperture. The operating conditions were: power $=300 \mathrm{~W}$ and $66.7 \% \mathrm{H}_{2}$ flow. 


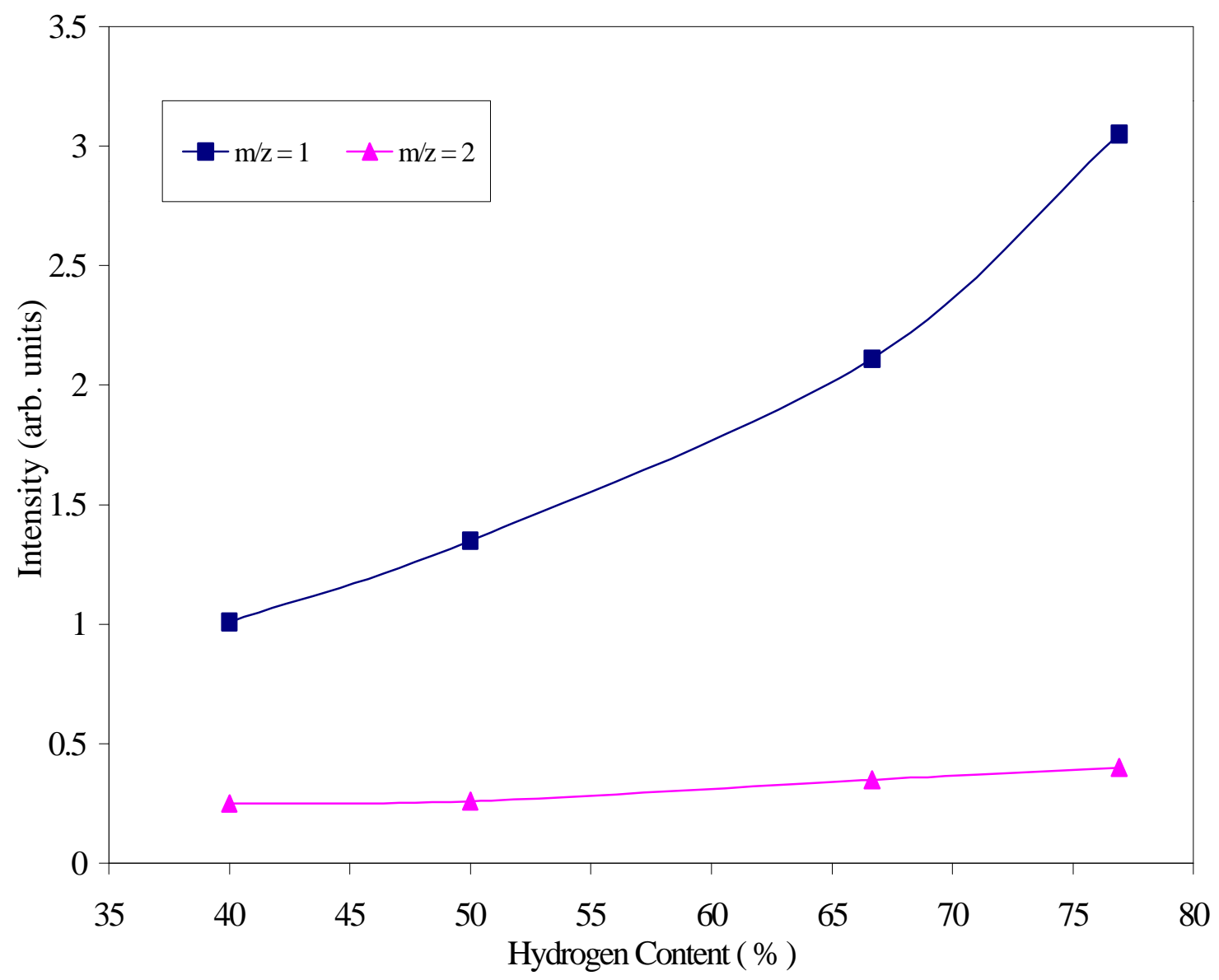

Figure 4.11 Effect of composition on ion content for the nine-hole aperture. The operating conditions were: power $=300 \mathrm{~W}$ and pressure $=5.8 \times 10^{-5}$ Torr. 


\subsection{Cleaning of CZT}

The cleaning of CZT with hydrogen plasma was investigated using the series of etch experiments described in this section. In all cases, the source was operated with the single hole aperture at a power of $300 \mathrm{~W}$, chamber pressure of $6 \times 10^{-5}$ Torr and $66.7 \%$ $\mathrm{H}_{2}$. For these conditions the beam composition was $7 \% \mathrm{H}, 8 \% \mathrm{H}_{2}, 40 \% \mathrm{H}^{+}$, and $45 \% \mathrm{H}_{2}^{+}$.

The CZT samples used in these experiments were grown using liquid phase epitaxy (LPE) by II-VI Incorporated (Pittsburgh, PA) and had been Br-methanol polished by the vendor. The samples were loaded into the analysis chamber without any additional wet etching.

XPS was used to monitor the changes of the chemical composition of the surface as a function of exposure to the hydrogen plasma. For some samples, charging was observed during XPS measurements. To compensate this, the fact that $\mathrm{Cd} 3 \mathrm{~d}-$ photoelectron line has a very small chemical shift that cannot be resolved in the XPS spectra was used to provide a reference [43].

Figure 4.12 shows a series of $\mathrm{Te} 3 \mathrm{~d}_{5 / 2}$ photoelectron spectra for increasing exposures to the hydrogen plasma at a substrate temperature of $\sim 30^{\circ} \mathrm{C}$ (room temperature). The initial spectrum $(\mathrm{t}=0 \mathrm{~min})$ is typical of $\mathrm{Br}$-methanol etched samples and consists of a photoelectron peak at $572.7 \mathrm{eV}(1.7 \mathrm{eV} \mathrm{FWHM})$ and $576.1 \mathrm{eV}(1.7 \mathrm{eV}$ FWHM). The peak at $572.7 \mathrm{eV}$ has been previously associated with metallic Te, [34, 35] while the peak at $576.1 \mathrm{eV}$ is representative of Te in the oxide state.

The initial spectrum is also consistent with the physical picture discussed by Hirsch et al. [33]. Their studies suggest that Br-methanol etch produces a Te rich amorphous layer (Te metal) which becomes oxidized upon exposure to air. An estimate 


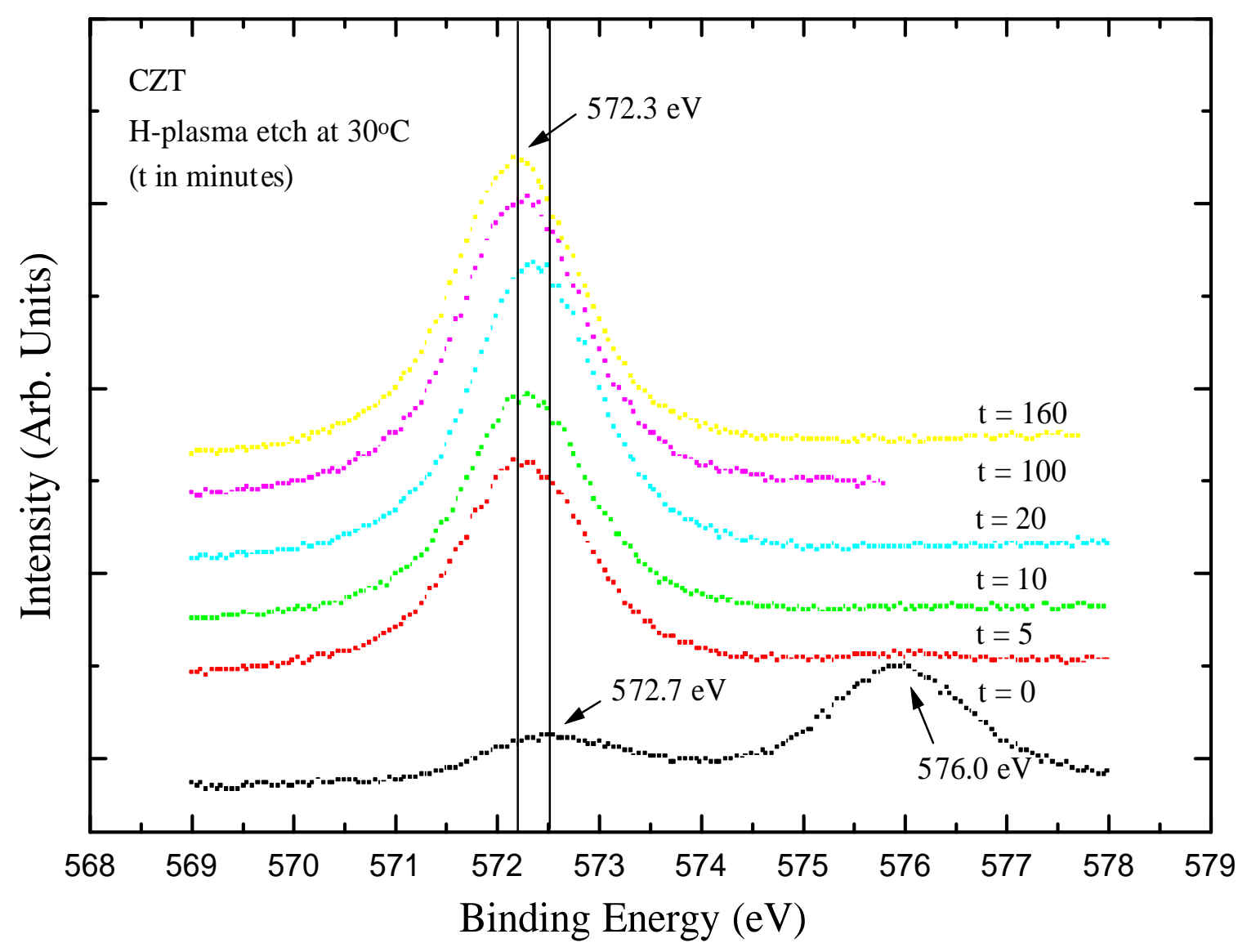

Figure 4.12 Te $3 \mathrm{~d}_{5 / 2}$ XPS spectra for a CZT substrate exposed to the H-plasma at $30^{\circ} \mathrm{C}$ for various times. 
of the oxide thickness can be obtained from the ratio of the oxide-Te and Te peaks from the initial spectrum. The thickness of the oxide $(\mathrm{t})$ and the underlying amorphous Te layer (t') are estimated as follows

$$
\begin{aligned}
& t=-\lambda \ln \left(\frac{\eta+1}{\beta+\eta+1}\right) \\
& t^{\prime}=-\lambda \ln \left(\frac{1}{\beta+\eta+1}\right)
\end{aligned}
$$

Here $\beta, \eta$ are functions of peak areas and number densities as given below.

$$
\begin{gathered}
\beta=\frac{I^{o} N^{S}}{I^{S} N^{O}} \\
\eta=\frac{I^{T} N^{S}}{I^{S} N^{T}}
\end{gathered}
$$

In these equations $I^{O}, I^{S}$ and $I^{T}$ are the peak areas for the oxide, substrate and tellurium overlayer and $N^{O}, N^{S}$ and $N^{T}$ are the number densities in the same order. In our calculations, the number densities for Te in amorphous $\mathrm{Te}$ and $\mathrm{Te}-\mathrm{O}$ were taken as 6.0 and $5.7 \mathrm{~cm}^{-3}$ respectively [44], while the value for CZT $\left(6.3 \mathrm{~cm}^{-3}\right)$ was approximated from values for $\mathrm{ZnTe}$ and CdTe.

The $\lambda$ in equations 4.5 and 4.6 is related to $\lambda_{p}$, the escape depth of the electrons and $\lambda_{i}$, the penetration depth of the x-rays by the equation.

$$
\frac{1}{\lambda}=\frac{1}{\lambda_{p} \cos \theta}+\frac{1}{\lambda_{i} \cos \alpha}
$$

Here the angles $\theta$ and $\alpha$ are angles made between a line perpendicular to the surface and the incident $x$-ray and emerging electron beams respectively. In our analysis system, $\theta \approx$ 
$10^{\circ}$ and $\alpha \approx 80^{\circ}$. Using the universal curve (Figure 3.3) the escape depth, $\lambda_{\mathrm{p}}$, can be estimated to be $1.5 \mathrm{~nm}$ for each of the constituents, while $\lambda_{\mathrm{i}} \gg \lambda_{\mathrm{p}}$ and can be taken to be infinite here. For the sample represented by the data shown in Figure 4.12, these considerations yield an estimated oxide thickness of $\sim 2.3 \mathrm{~nm}$ and an amorphous Te overlayer of $\sim 6.5 \mathrm{~nm}$.

As is shown in Figure 4.12, the complete removal of the oxide occurs in the first 5 minutes of etching. As the etch proceeds, the peak at $572.7 \mathrm{eV}$ shifts to lower binding energies and attains a value of $572.3 \mathrm{eV}(1.5 \mathrm{eV}$ FWHM) which is representative of Te in CdTe, CZT and CMT [36]. Careful peak fitting shows that at intermediate etch times the spectrum is a combination of these two peaks.

Cd $3 d_{5 / 2}$ and the $\mathrm{Zn} 2 \mathrm{p}_{3 / 2}$ photoelectron peaks corresponding to the Te $3 \mathrm{~d}_{5 / 2}$ spectra shown in Figure 4.12 did not exhibit a characteristic oxide peak. As documented by several groups, $[43,45]$ these peaks do not exhibit a large chemical shift like Te. The Cd peaks are known to undergo a slight broadening (due to an unresolved small chemical shift). In our studies we find that the FWHM for the $\mathrm{Cd} 3 \mathrm{~d}_{5 / 2}$ peak is $1.3 \mathrm{eV}$ both before and after the $\mathrm{TeO}_{2}$ removal. The $\mathrm{Zn} 2 \mathrm{p}_{3 / 2}$ peaks were very weak initially and it was difficult to extract them from the noise. As the oxide was removed, however, better signal to noise ratios were achieved. These results, though not conclusive suggest that $\mathrm{Cd}$ and $\mathrm{Zn}$ play little if any role in the oxide.

The surface composition of the as received and etched substrates were determine using equation 3.1, measured peak areas, and elemental sensitivity factors. The specific sensitivity factors used in these calculations are identified as the "input values" in Table 4.1 . 


\begin{tabular}{|c|c|c|c|c|}
\hline $\mathbf{T e ~ 3 d}_{\mathbf{5 / 2}}$ & $\mathbf{C d ~ 3 d}_{\mathbf{5 / 2}}$ & $\mathbf{Z n ~ 2} \mathbf{p}_{\mathbf{3} / \mathbf{2}}$ & $\mathbf{H g} \mathbf{4 f}$ & \\
\hline 1.000 & 0.560 & 0.651 & 0.470 & Input Values \\
\hline 1.000 & 0.560 & & 0.470 & Hirch et al [46] \\
\hline 1.000 & 0.640 & & 0.530 & Nitz [47] \\
\hline 1.000 & 0.533 & 0.651 & & This study \\
\hline 1.000 & 0.697 & 0.653 & 1.212 & Handbook [39] \\
\hline
\end{tabular}

Table 4.3 Elemental sensitivity factors determined experimentally and from literature 
As noted in chapter 3, the sensitivity factor values identified in Table 4.1 as results of this study were established using the assumption that $\mathrm{Ar}^{+}$ion etching produces a stoichiometric surface. The same is true of the values reported by Nitz [47]. The validity of this assumption is difficult to verify although it is frequently made. The values reported by Hirsch [46] were established using MBE grown films of known composition and are therefore more reliable we believe. Consequently, we used these as the input values for $\mathrm{Cd}$, Te and $\mathrm{Hg}$. Since no value was available for $\mathrm{Zn}$, our result was used. This value is in reasonable agreement with the handbook value.

A propagation of error analyses for the surface composition was performed based on the uncertainties in the sensitivity factors (range of values indicated in Table 4.3) and peak areas. The maximum errors associated with the composition of $\mathrm{Te}, \mathrm{Cd}$ and $\mathrm{Zn}$ were found out to be $\pm 2 \%, \pm 6 \%$ and $\pm 1 \%$ respectively. These are expressed as error bars in Figure 4.13.

The results of the composition versus etch time measurements are shown in Figure 4.13. In general, the first 5 minutes of etching resulted in the complete removal of the Te oxide and amorphous Te overlayer and an increase in the near surface concentration of $\mathrm{Cd}$ and $\mathrm{Te}$ in $\mathrm{CZT}$ (Te in the matrix), and a slight decrease in the concentration of $\mathrm{Zn}$. With continued etching, the $\mathrm{Cd}$ concentration continued to decrease while the $\mathrm{Te}$ in $\mathrm{CZT}$ and $\mathrm{Zn}$ concentrations increased slightly. The relative atomic concentrations approximately indicate one Te for each remaining $\mathrm{Zn}$ and $\mathrm{Cd}$ combined. This implies Te removal as well as Cd removal. In all cases, the composition of the hydrogen plasma etched CZT surface was CdTe depleted. 


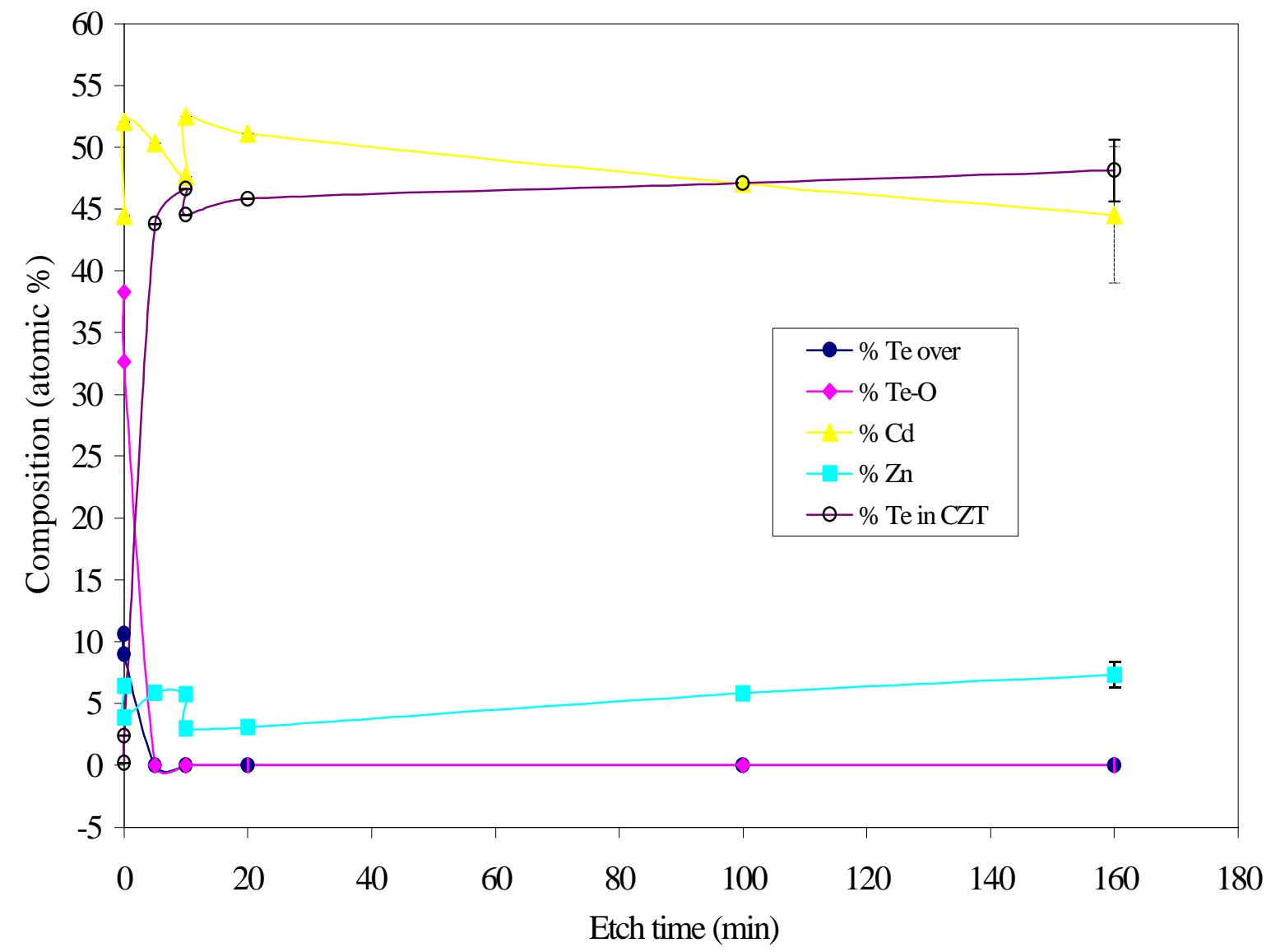

Figure 4.13 Composition vs. etch time for the CZT substrate. 
A similar series of experiments was performed while holding the substrate temperature at $300^{\circ} \mathrm{C}$. These results are shown in Figure 4.14 . Based on an analysis of the initial spectrum, the estimated thickness of the oxide is $0.6 \mathrm{~nm}$ and the Te overlayer is 2.9 $\mathrm{nm}$. To evaluate the thermal stability of the amorphous Te and Te oxide overlayers, the substrate was annealed for 15 minutes at $300^{\circ} \mathrm{C}$. This resulted in the complete removal of the amorphous Te overlayer; a decrease in concentration of $\mathrm{Te}$ oxide and $\mathrm{Cd}$; and a increase in the concentration of $\mathrm{Zn}$, Te in CZT. The oxide was then completely removed in the first 5 minutes of plasma etching with a decrease in the concentration of $\mathrm{Zn}, \mathrm{Cd}$ and an increase in the concentration of Te in CZT. The long term plasma etching at $300^{\circ} \mathrm{C}$ shows a trend very similar to the long term etching of CZT at room temperature. The maximum errors associated with the composition of Te in CZT, $\mathrm{Cd}$ and $\mathrm{Zn}$ were found out to be $\pm 2 \%, \pm 4 \%$ and $\pm 1 \%$ respectively.

\subsection{Etching of CMT using a Hydrogen Plasma}

The CMT samples used in these experiments were grown using LPE and had been Br-methanol etched. Figure 4.15 shows a series of $\mathrm{Te} 3 \mathrm{~d}_{5 / 2}$ spectra for increasing exposures to the hydrogen plasma at a substrate temperature of $30^{\circ} \mathrm{C}$ (room temperature). The photoelectron peaks at $572.7 \mathrm{eV}$ and $576.1 \mathrm{eV}$, as previously discussed, are associated with the amorphous Te overlayer and the $\mathrm{TeO}_{2}$ layer. Based on an analysis of these peaks, the estimated thickness of the oxide is $1.3 \mathrm{~nm}$ and the Te overlayer is 4.3 nm. The corresponding $\mathrm{Cd} 3 \mathrm{~d}_{5 / 2}$ and $\mathrm{Hg} 4 \mathrm{f}_{7 / 2}$ photoelectron spectra did not exhibit a characteristic oxide peak. Figure 4.16 shows the variation of the surface composition as a function of the etch time. 


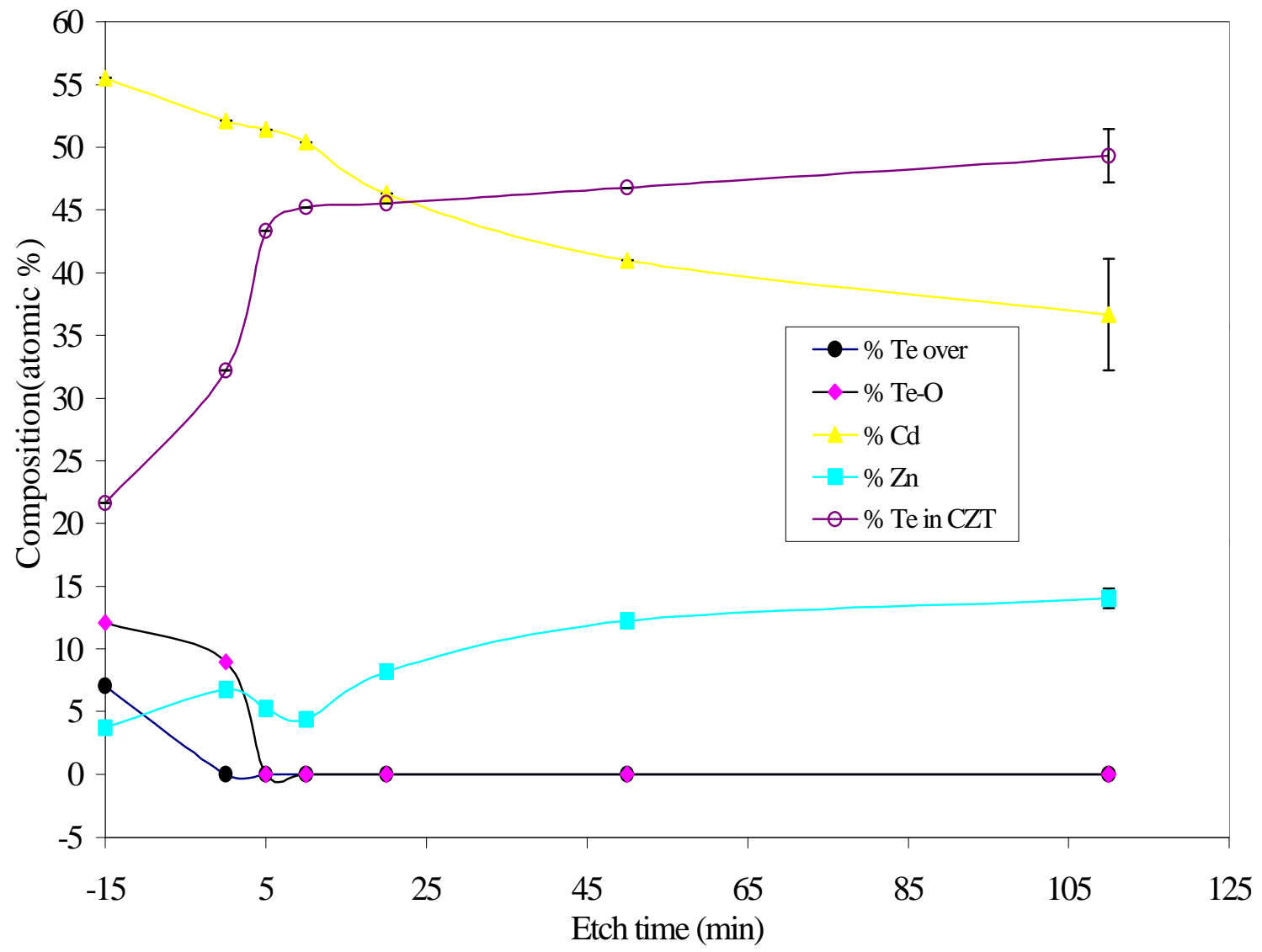

Figure 4.14 Composition vs. etch time for the CZT substrate at $300^{\circ} \mathrm{C}$. 


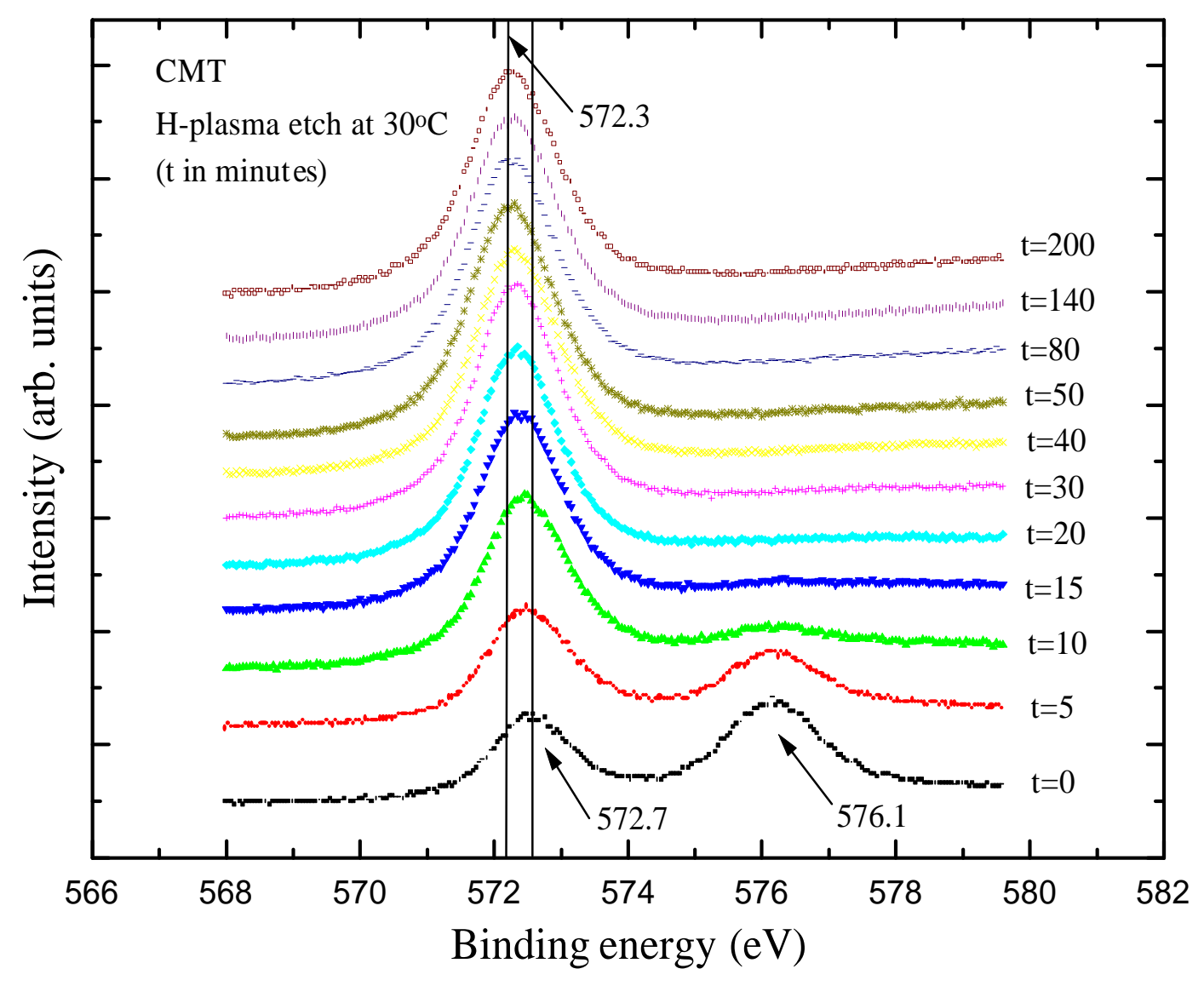

Figure 4.15 Te $3 \mathrm{~d}_{5 / 2}$ XPS spectra for a CMT substrate exposed to the H-plasma at $30^{\circ} \mathrm{C}$ for various times. 


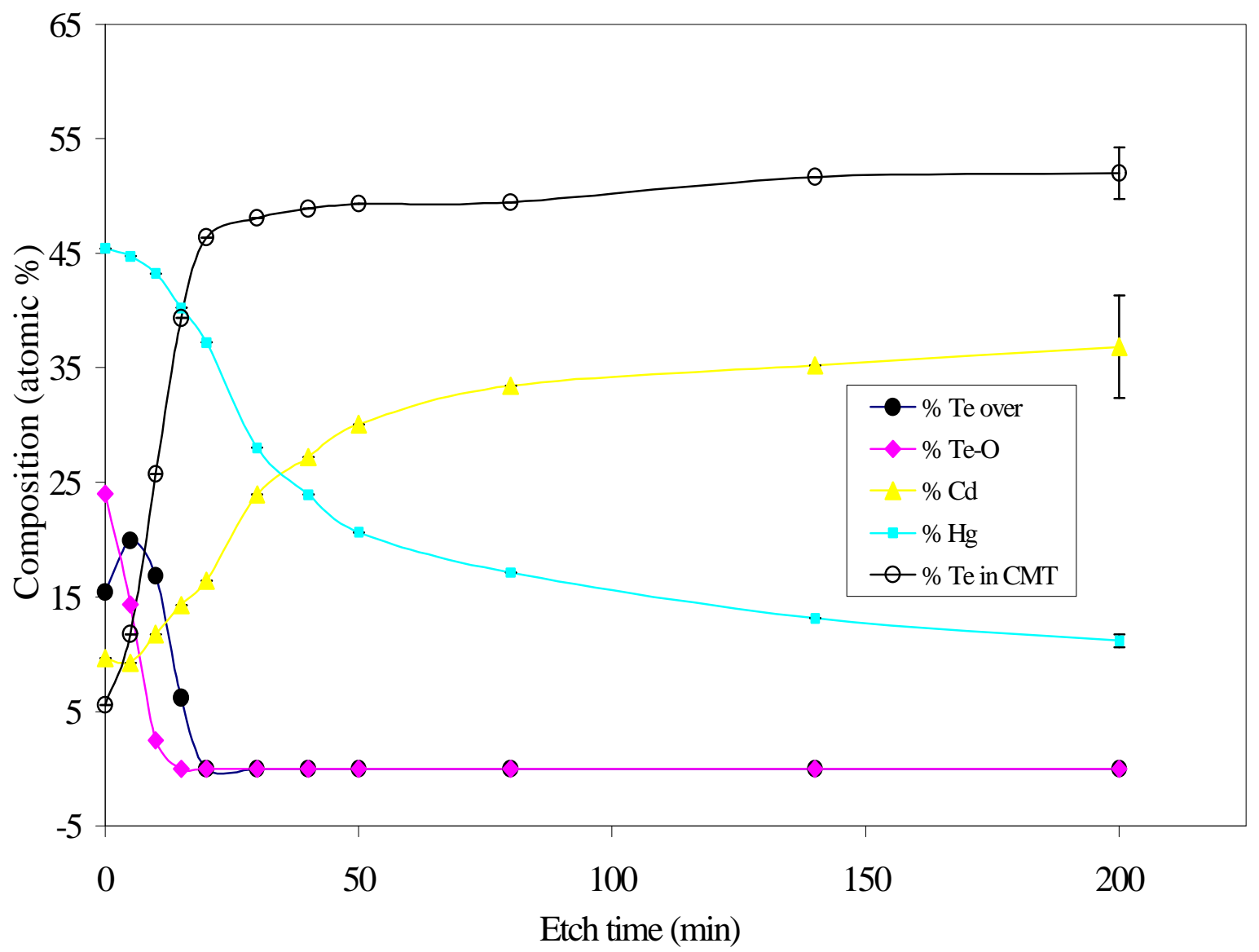

Figure 4.16 Composition vs. etch time for the CMT substrate. 
Surface composition of the as received and etched substrate was determined as before using equation 3.1, measured peak areas, and elemental sensitivity factors. In general, an increase in the near surface concentration of $\mathrm{Cd}$, Te in CMT and a decrease in the concentration of $\mathrm{Hg}$ were observed during the first 5-10 minutes of etching. There is also an increase in the amorphous Te during this stage of etching. After the complete removal of the oxide, which occurs around 15 minutes, the etching of Te overlayer occurs rapidly. With continued etching, the $\mathrm{Cd}$ and $\mathrm{Te}$ in CMT increase with the Te in CMT approaching a relatively constant value near $50 \%$. However, the $\mathrm{Cd}$ and $\mathrm{Hg}$ plots do not saturate. Finally, the composition of the CMT surface was HgTe depleted after long-term etching. The long-term CMT etching observed here with the hydrogen plasma source is very similar to that observed for the thermal hydrogen source used by Hirsch et al [33]. The primary difference is the fact that the $\mathrm{Hg}, \mathrm{Cd}$ concentrations do not appear to saturate. The maximum errors associated with the composition of Te in CMT, $\mathrm{Cd}$ and $\mathrm{Hg}$ were found out to be $\pm 2 \%, \pm 5 \%$ and $\pm 1 \%$ respectively.

The etch mechanism of the cleaning of CMT, CZT surfaces may be explained with a simple surface chemistry model. Br-methanol etching of CZT and CMT substrates leaves behind a Te overlayer which becomes oxidized in the air. The oxide is removed by the formation of volatile species, $\mathrm{H}_{2} \mathrm{O}$ and $\mathrm{TeH}_{2}$. Similarly the amorphous Te overlayer is removed by the reaction

$$
\mathrm{Te}+2 \mathrm{H} \rightarrow \mathrm{TeH}_{2} \boldsymbol{\uparrow}
$$

A reaction involving breaking the relatively weak CdTe bond must also occur since $\mathrm{CdTe}$ depletion is observed in the near-surface region as indicated by Figure 4.13. This can be explained by the reaction 


\section{$\mathrm{CdTe}+2 \mathrm{H} \longrightarrow \mathrm{Cd} \boldsymbol{\uparrow}+\mathrm{TeH}_{2} \uparrow$}

Here the $\mathrm{Cd}$ is thermally desorbed. After extended exposure to the hydrogen plasma, the surface becomes ZnTe rich suggesting the possible formation of a ZnTe blocking layer.

In the case of CMT, we can see from Figure 4.16 that there is a preferential etching of HgTe over CdTe. This again can be explained with the following reaction

$$
\mathrm{HgTe}+2 \mathrm{H} \longrightarrow \mathrm{Hg} \boldsymbol{\varphi}+\mathrm{TeH}_{2} \boldsymbol{\uparrow}
$$

The Hg is thermally desorbed and the etching of Te bound to $\mathrm{Hg}$ occurs when exposed to the hydrogen plasma. The mechanism is very much similar to the CZT, the difference being that the breaking of HgTe bond occurs here and not CdTe. This is because the CdTe bond in CMT is actually stronger than the CdTe bond in CZT. Infact in the case of $\mathrm{CZT}$, the ZnTe bond is the stronger of the two. $[8,18]$

\subsection{Si (100) Substrate Cleaning in the Hydrogen Plasma}

Given the high level of ions in the remote rf-hydrogen plasma, experiments were performed to determine if it was sufficiently aggressive to remove the oxide from silicon substrates. To this end, as received and Fenner etched substrates were exposed to the hydrogen plasma for periods of 30 to 60 minutes at room temperature, $500^{\circ} \mathrm{C}$, and $700^{\circ} \mathrm{C}$. These results are summarized in Figures 4.17 to 4.20 .

Figure 4.17 shows the Si 2p XPS peak before and after 30 minutes of etching. The peak at $103.6 \mathrm{eV}$ corresponds to the native oxide layer while that at $99.7 \mathrm{eV}$ corresponds to the elemental silicon in the underlying substrate. Based on an analysis of these two peaks in this $\mathrm{t}=0$ spectrum, the thickness of the oxide is estimated to be $0.7 \mathrm{~nm}$. After 30 minutes of etching it appears that little or no oxide has been removed. 


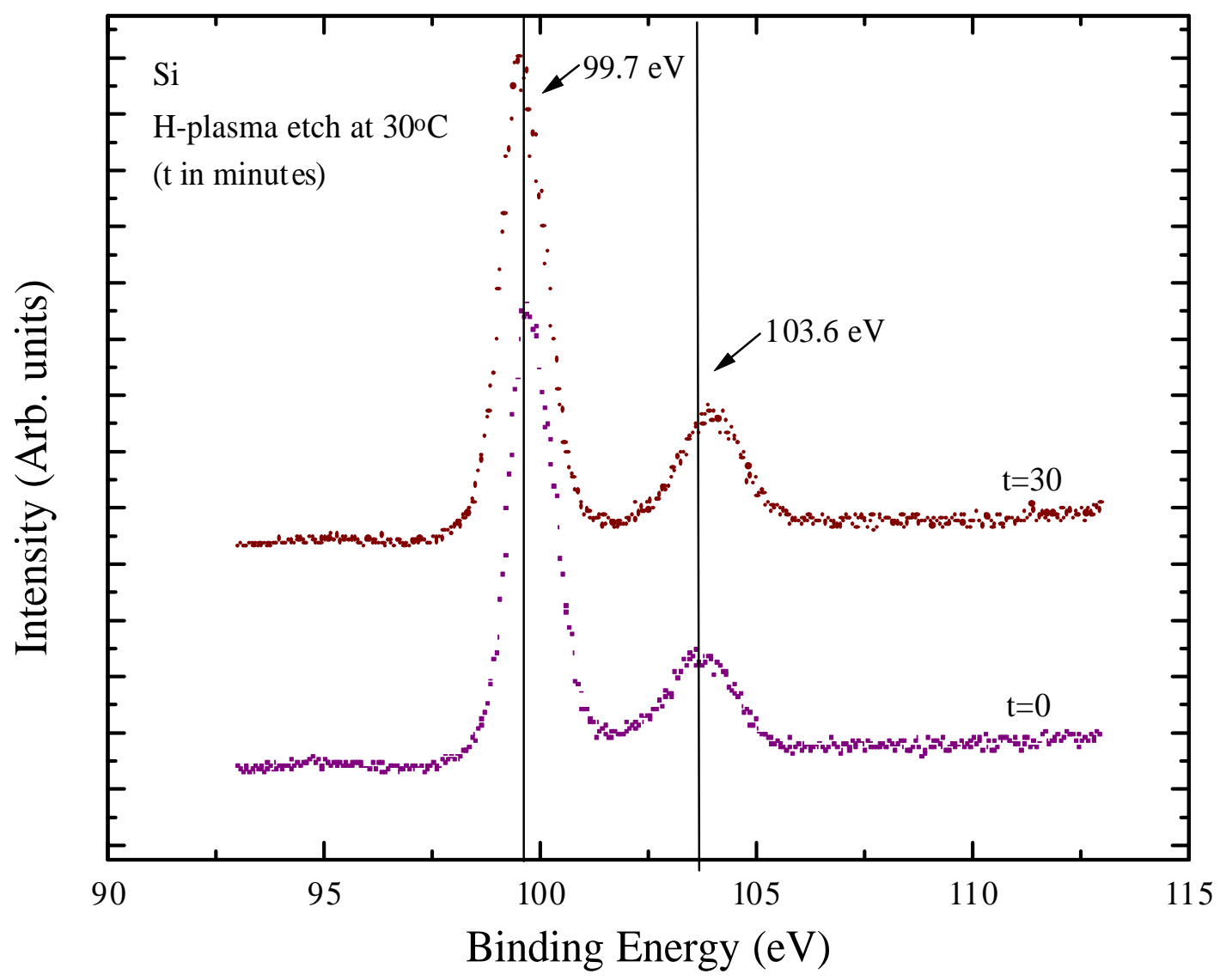

Figure 4.17 Si 2p XPS spectra for an as received Si-substrate $(\mathrm{t}=0)$ and after 30 minutes of etching $(t=30)$. 


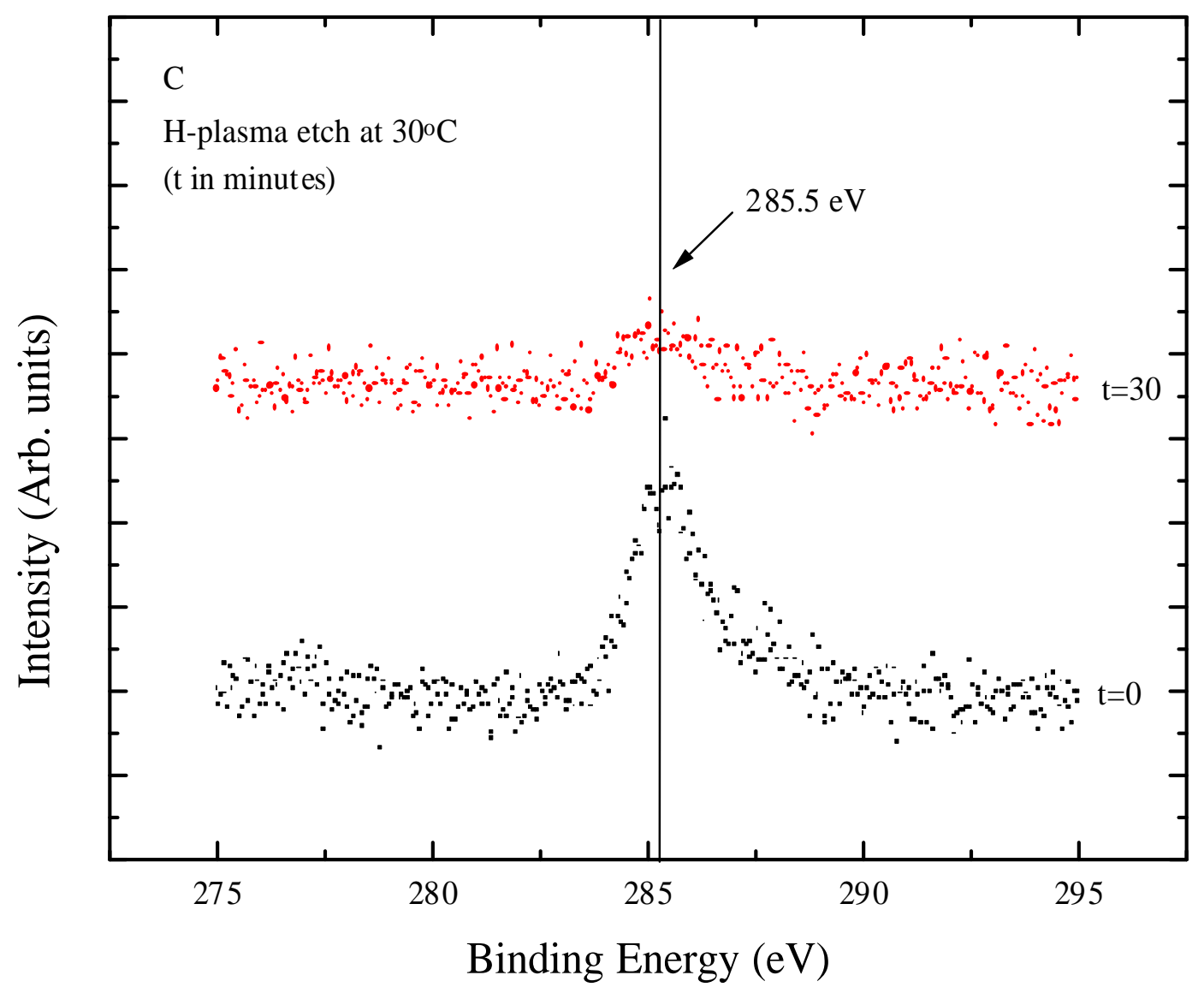

Figure 4.18 C 1s XPS spectra for an as received Si-substrate $(\mathrm{t}=0)$ and after 30 minutes of etching $(t=30)$. 


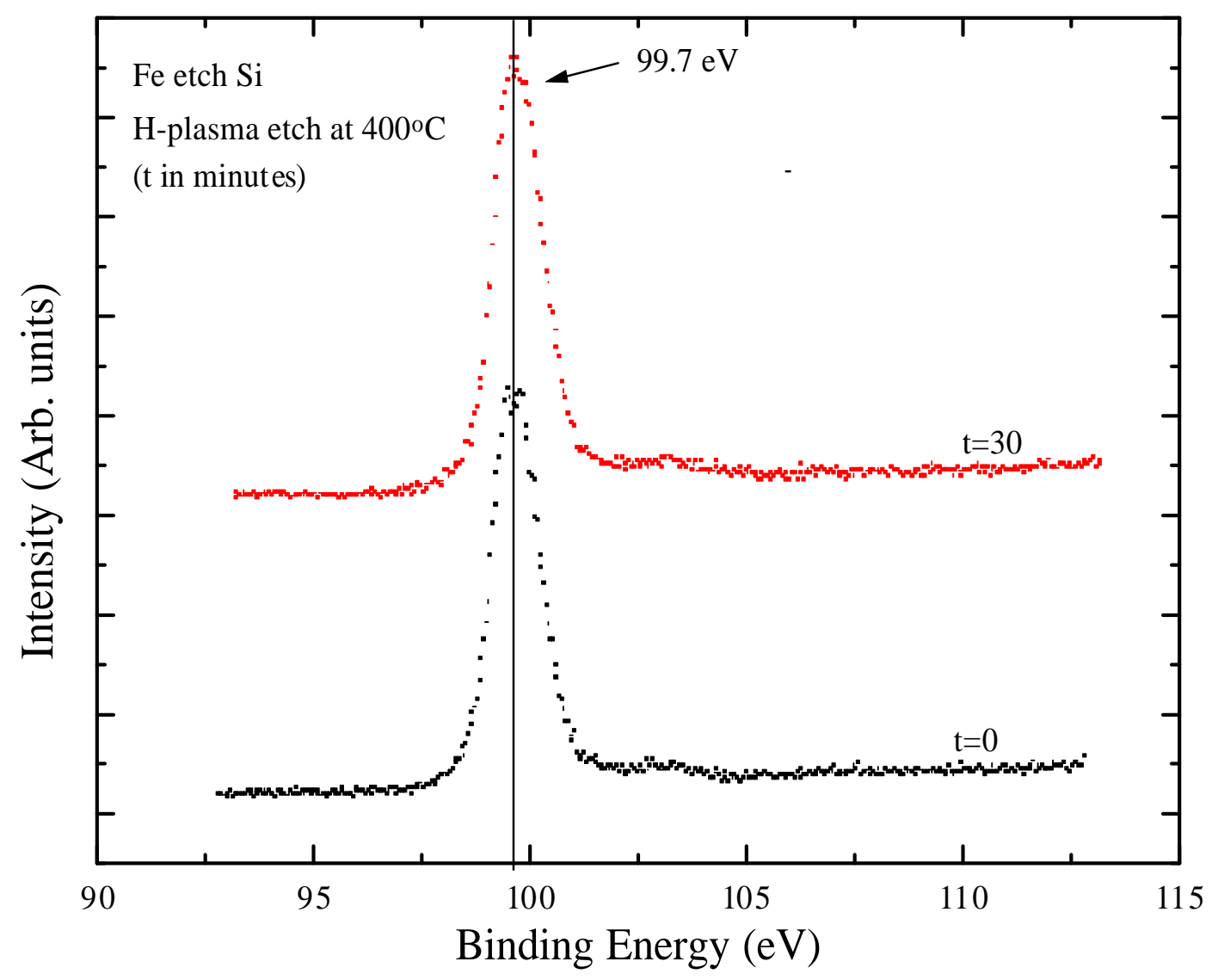

Figure 4.19 Si 2p XPS spectra for a Fenner etched Si-substrate $(\mathrm{t}=0)$ and after 30 minutes of etching $(t=30)$. 


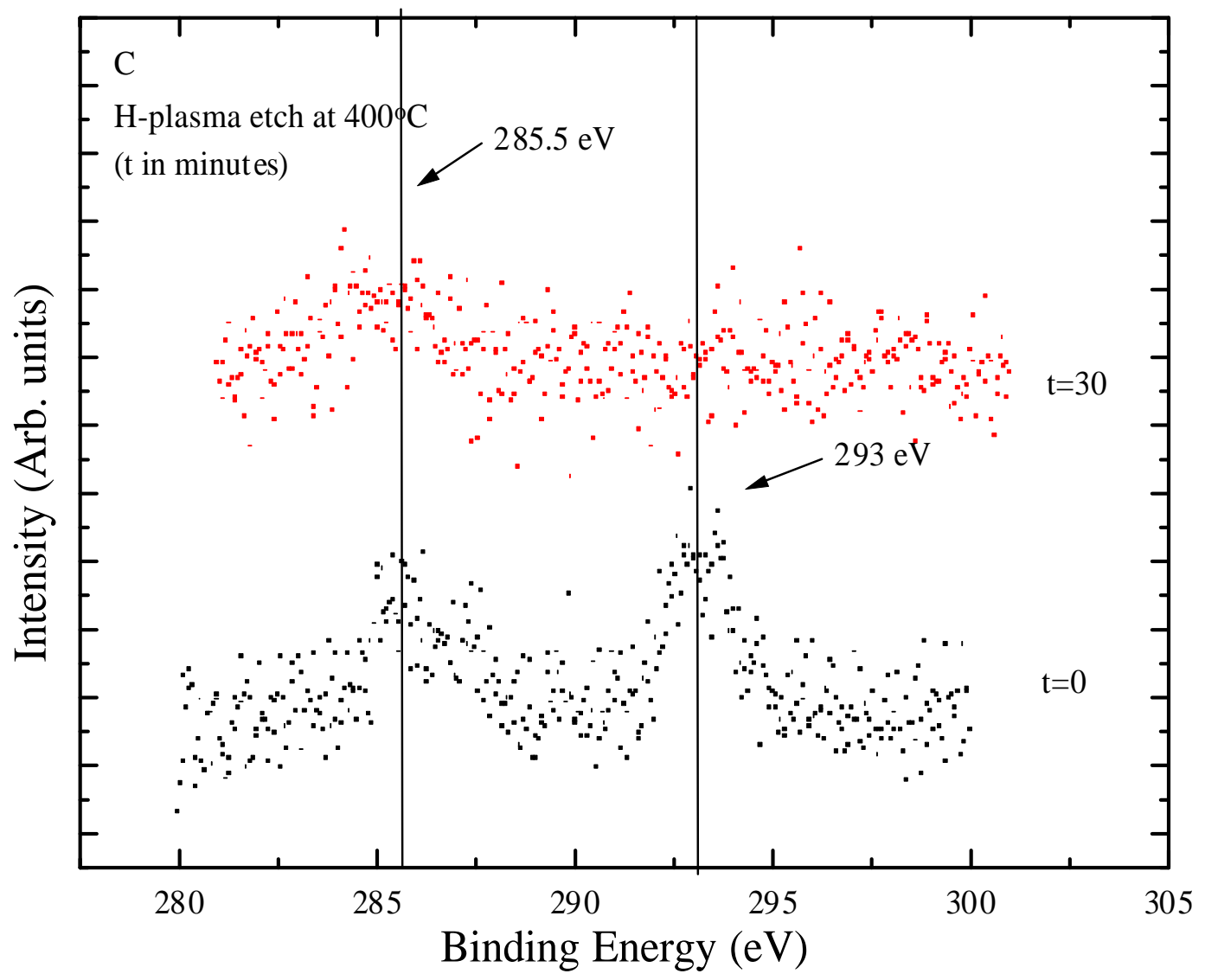

Figure 4.20 C 1s XPS spectra for a Fenner etched Si-substrate $(t=0)$ and after 30 minutes of etching $(\mathrm{t}=30)$. 
Figure 4.18 clearly illustrates, however, the removal of C-contamination from the surface during this period. Figure 4.19 and 4.20 show similar spectra for a Fenner etched sample. After 30 minutes of etching it appears that little or no oxide has been removed. Figure 4.20 clearly illustrates the removal of carbon contaminants from the surface. Also notice that the $\mathrm{C}$-1s peak at $293 \mathrm{eV}$ which corresponds to $\mathrm{CF}_{\mathrm{x}}$ surface species has also been removed. The spectra taken after the high temperature cleaning also clearly indicated little or no removal of oxygen. 


\section{Conclusions and Recommendations}

\subsection{Conclusions}

In this study, remote rf-hydrogen plasma etching II-VI and silicon semiconductor surfaces has been studied as a preparation for subsequent deposition in molecular beam and gas source molecular beam epitaxy environments. These studies included both mass spectrometric characterization of the plasma and in-situ XPS analysis of the etched substrates.

These studies provide an understanding of the dependence of the plasma species distribution on plasma parameters including pressure, chamber pressure and flow rate for a single hole aperture and a nine-hole aperture. It was found that the ion levels for the single hole aperture are significantly greater than for the nine-hole aperture. Based on the experimental results, the plasma etching studies were performed with the single hole aperture at a power of $300 \mathrm{~W}$, a chamber pressure of $6 \times 10^{-5}$ Torr, and an $\mathrm{H}_{2}$ concentration of $66.7 \%$.

The remote rf-hydrogen plasma was found, suitable for cleaning CMT \& CZT semiconductor substrates at room temperature. It removed the Te-oxide, amorphous-Te, and hydrocarbon contaminants completely and produced a surface very close to stoichiometry. These results are very similar to those obtained by Hirsch et al using a thermal $\mathrm{H}$-atom source. The remote rf-hydrogen plasma was also successful in cleaning CZT at a temperature of $300^{\circ} \mathrm{C}$. The remote rf-hydrogen plasma was not sufficiently active to remove the native oxide from silicon for either as-received or for Fenner-etched samples at substrate temperatures of $30^{\circ} \mathrm{C}, 500^{\circ} \mathrm{C}$ and $700^{\circ} \mathrm{C}$. The plasma was, however, 
very effective at removing the $\mathrm{CH}_{\mathrm{x}}$ (hydrocarbon) and $\mathrm{CF}_{\mathrm{x}}$ contaminants from the asreceived and Fenner-etched silicon samples.

The primary difference between our results for CMT and those of Hirsch et al is that for the atom source, changes in surface composition appeared to truly saturate with etch time, In contrast, true saturation did not occur for the plasma source. This may be consequence of the fact that etching, in the case of the rf-plasma, involves chemical \& physical processes, while in the case of the atom source the mechanism is strictly chemical. That is, the energy carried by the hydrogen ions, although less than $2 \mathrm{eV}$, may provide enhanced etching compared with the stictly chemical effects of hydorgen atoms.

\subsection{Recommendations}

The present experiments show that the oxide and amorphous Te associated with Br-methanol etched CZT could be removed by exposure to hydrogen plasma at room temperature. To understand more about the oxide on CZT, its stability, and the mechanism by which cleaning occurs, more samples have to be analyzed. Also AFM analysis of the cleaned substrates should be performed to determine the surface roughness and microstructure. In addition, studies to obtain better elemental sensitivity factor values should be performed.

The ion dominated hydrogen plasma appears to be very aggressive because it seems to remove the oxide in about 5-10 minutes. It would be interesting to investigate the effects of the plasma under milder conditions. For example a 9-hole aperture could be used under conditions of lower power and/or lower pressure. This could increase the process window for obtaining a stoichiometric surface. A direct measurement of the $\mathrm{H}_{2}$ 
flux at the substrate using a beam flux monitor would allow quantitative determination of the fluxes. 


\section{References}

1. H. M. Grimes, Texas-Instruments-Technical-Journal. 12, 5 (1995).

2. Z. Rymuza, M. Misiak, L. Kuhn, K. Schmidt -Szalowski, and Z. Rzanek-Boroch, Microsystem - Technologies. 5, 181 (1999).

3. S. E. Hug, L. Chen, and P. D. Prewett, Microelectronic-Engineering. 27, 95 (1995).

4. J. M. Lannon, J. S. Gold, and C. D. Stinespring, Mat. Res. Soc. Symp. Proc. 339, 63 (1994).

5. H. Hobert, H. H. Dunken, G. Peiter, W. Stier, M. Diegel, and H. Stafast, Appl. Phys. A 69, 69 (1999).

6. T. Lei, T. D. Moustakas, R. J. Graham, Y. He, and S. J. Berkowitz, J. Appl. Phys. 71, 4933 (1992).

7. G. E. Becker and J. C. Bean, J. Appl. Phys.48, 3395 (1977).

8. M. A. Foad, C. D. W. Wilkinson, C. Dunscomb, and R. H. Williams, Appl. Phys. Lett. 60, 2531 (1992).

9. W. Kern, Electrochem. Soc. Proc. 3, 90 (1990).

10. D. B. Fenner, D. K. Biegelson, and R. D. Brigans, J. Appl. Phys. 66, 419 (1989).

11. V. Atluri, N. Herbots, D. Dagel, S. Bhagwat, and S. Whaley, Nuclear Instruments and Methods in Physics Research B 118, 144(1996).

12. T. W. Chan, X. J. Bao, P. J. Sides, and E. I. KO.EI, Mater. Res. Soc. Symp. Proc., 259, 275 (1992).

13. W. H. Chang, T. Lee, and W. M. Lau, J. Appl. Phys. 68, 4816 (1990).

14. M. Seelmann-Eggebert and H. J. Richter, J. Vac. Sci. Technol. A 6, 1371 (1988). 
15. G. Holmen and H. Jacobsson, J. Appl. Phys. 68, 2962 (1990).

16. J. Pelletier, Y. Arnal, M. Pons, and A. Inard, Jap. J. Appl. Phys. I 29, 1846 (1990).

17. R. J. Carter, T. P. Schneider, J. S. Montgomery, and R. J. Nemanich, J. Electrochem. Soc. 141, 3136 (1994).

18. R. C. Keller, H. Zimmerman, M. Seelmann, and H. J. Richter, Surface Cleaning and Etching of CdZnTe and CdTe in $\mathrm{H}_{2} / \mathrm{Ar}$ ECR Plasmas.

19. Plasma-Assisted Chemical Vapor Deposition, V. S. Nguyen.

20. G. H. Winton, N. Warrington, and L. Faraone, J. Vac. Sci. Technol. A 14, 2325 (1996).

21. E. D. Atanassova and A. V. Shopov, Applications. Surf. Sci.16, 395 (1983).

22. C. J. Mogab, A. C. Adams, and D.L. Flamm, J. Appl. Phys. 49, 3796 (1978).

23. C. W. Nam, S. Ashok, W. Tsai, and M. E. Day, J. Vac. Sci. Technol. B 12, 3010 (1994).

24. B. Anthony, L. Breaux, T. Hsu, S. Banerjee, and A. Tasch, J. Vac. Sci. Technol. B 7, 621 (1989).

25. I. Suemune, Y. Kunitsugu, Y. Tanaka, Y. Kan, and M. Yamanishi, Appl. Phys. Lett. 53, 2173 (1988).

26. Hyoun-woo Kim and Rafael Reif, Thin Solid Films 289, 192 (1996).

27. M. Delfino, S. Salimian, D. Hodul, A. Ellingboe, and W. Tsai, J. Appl. Phys. 71, 1001 (1992).

28. M. Ishii, K. Nakashima, I. Tajima, and M. Yamamoto, Appl. Phys. Lett. 58, 1378 (1991).

29. H. Shimomura, Y. Okada, and M. Kawabe, Jpn. J. Appl. Phys. 31, L628 (1992). 
30. J. E. Spencer, T. R. Schimert, J. H. Dinan, D. Endres, and T. R. Hayes, J. Vac. Sci. Technol. A 8, 1690 (1990).

31. U. Solzbach and H. J. Richter, Surface Science 97, 191 (1980).

32. Keller, M. Seelmann-Eggebert, and H. J. Richter, Appl. Phys. Lett. 67, 3750 (1995).

33. L. S. Hirsch, K. S. Ziemer, M. R. Richards Babb, C. D. Stinespring, T. H. Myers, and Thierry Colin, J. Electron. Mat. 27, 651 (1998).

34. T. S. Sun, S. P. Buchner, and N. E. Byer, J. Vac. Sci. Technol. 17, 1067 (1980).

35. S. W. Garentroom and N. Winograd, J. Chem. Phys. 67, 3500 (1977).

36. W. E. Swartz, K. J. Wynne, and D. M. Hercules, Anal. Chem. 43, 1884 (1971).

37. Oxford Applied Research, Crawley Mill, Witney, Oxfordshire OX8 5TJ, UK.

38. W. E. Hoke, P. J. Lemonias, and D. G. Weir, J. Crystal Growth 111, 1024 (1991).

39. Handbook of X-ray Photoelectron Spectroscopy, Physical Electronics, Inc.

40. M. P. Seah and W. A. Dench, Surf. Interface Anal. 1, 2 (1979).

41. Ionizer control, Instruction Manual, ABB Extrel, 575 Epsilon Dr., Pittsburgh, Pennsylvania 15238.

42. Characterization and modeling of a RF plasma source of active nitrogen for Gallium Nitride growth, S. Kumar, WVU, 1996.

43. R. F. C. Farrow, P. H. J. Dennis, H. E. Bishop, N. R. Smart, and J. T. M. Wotherspoon, Thin Solid Films 88, 87 (1982).

44. R. C. Weast, Editor, CRC Handbook of Chemistry and Physics, CRC Press Inc. (Boca Raton, FL), B68-161, 1985. 
45. G. D. Davis, T. S. Sun, S. P. Buncher, and N. E. Byer, J. Vac. Sci. Technol. 19, $472(1981)$.

46. L. S. Hirsch, R. Haakenaasen, T. Colin, K. S. Ziemer, C. D. Stinespring, S. Lovold, and T. H. Myers, J. Electron. Mat. 28, 810 (1999).

47. H. M. Nitz, O. Ganschow, U. Kaiser, L. Wiedmann, and A. Benninghoven, Surface Sci. 104, 365 (1981). 